\title{
SARS-CoV-2 can recruit a haem metabolite to evade antibody immunity
}

\begin{abstract}
Annachiara Rosa ${ }^{1}$, Valerie E. Pye', Carl Graham², Luke Muir ${ }^{3}$, Jeffrey Seow ${ }^{2}$, Kevin W. Ng ${ }^{4}$, Nicola J. Cook', Chloe Rees-Spear ${ }^{3}$, Eleanor Parker ${ }^{5}$, Mariana Silva dos Santos ${ }^{6}$, Carolina Rosadas ${ }^{5}$, Alberto Susana ${ }^{7}$, Hefin Rhys $^{8}$, Andrea Nans ${ }^{9}$, Laura Masino ${ }^{9}$, Chloe Roustan ${ }^{9}$, Evangelos Christodoulou ${ }^{9}$, Rachel Ulferts ${ }^{10}$, Antoni G. Wrobel $^{11}$, Charlotte-Eve Short ${ }^{5}$, Michael Fertleman ${ }^{12}$, Rogier W. Sanders ${ }^{13,14}$, Judith Heaney ${ }^{15,16}$, Moira Spyer ${ }^{15,16,17}$, Svend Kjar ${ }^{9}$, Andy Riddell ${ }^{8}$, Michael H. Malim², Rupert Beale ${ }^{10}$, James I. MacRae ${ }^{6}$, Graham P. Taylor $^{5}$, Eleni Nastouli15,16,17, Marit J. van Gils ${ }^{13}$, Peter B. Rosenthal ${ }^{18}$, Massimo Pizzato ${ }^{7}$, Myra O. McClure ${ }^{5}$, Richard S. Tedder ${ }^{5}$, George Kassiotis ${ }^{4,5} \uparrow$, Laura E. McCoy ${ }^{3} \uparrow$, Katie J. Doores ${ }^{2} \uparrow$, and Peter Cherepanov ${ }^{1,5} \uparrow$

${ }^{1}$ Chromatin Structure and Mobile DNA Laboratory, The Francis Crick Institute, London, UK. ${ }^{2}$ Department of Infectious Diseases, School of Immunology \& Microbial Sciences, King's College London, UK. ${ }^{3}$ Institute of Immunity and Transplantation, Division of Infection and Immunity, University College London, London, UK. ${ }^{4}$ Retroviral Immunology Laboratory, The Francis Crick Institute, London, UK. ${ }^{5}$ Department of Infectious Disease, St-Mary's Campus, Imperial College London, UK. ${ }^{6}$ Metabolomics Science Technology Platform, The Francis Crick Institute, London, UK. ${ }^{7}$ Department of Cellular, Computational and Integrative Biology, University of Trento, Italy. ${ }^{8}$ Flow Cytometry Science and Technology Platform, The Francis Crick Institute, London, UK. ${ }^{9}$ Structural Biology Science Technology Platform, The Francis Crick Institute, London, UK. ${ }^{10} \mathrm{Cell}$ Biology of Infection Laboratory, The Francis Crick Institute, London, UK. "'Structural Biology of Disease Processes Laboratory, The Francis Crick Institute, London, UK. ${ }^{12}$ Cutrale Perioperative \& Ageing Group, Imperial College London, UK. ${ }^{13}$ Department of Medical Microbiology, Amsterdam UMC, University of Amsterdam, Amsterdam Institute for Infection and Immunity, Amsterdam, Netherlands. ${ }^{14}$ Weill Medical College of Cornell University, New York, US. ${ }^{15}$ Advanced Pathogen Diagnostic Unit, University College London Hospitals NHS Foundation Trust, London, UK. ${ }^{16}$ Crick COVID-19 Consortium, The Francis Crick Institute, London, UK. ${ }^{17}$ Department of Infection, Immunity and Inflammation, UCL Great Ormond Street Institute of Child Health. ${ }^{18}$ Structural Biology of Cells and Viruses Laboratory, The Francis Crick Institute, London, UK.

†Corresponding author. Email: Peter.Cherepanov@crick.ac.uk (PC); Katie.Doores@kcl.ac.uk (KJD); L.McCoy@ucl.ac.uk (LEM); George.Kassiotis@crick.ac.uk (GK).
\end{abstract}

The coronaviral spike is the dominant viral antigen and the target of neutralizing antibodies. We show that SARS-CoV-2 spike binds biliverdin and bilirubin, the tetrapyrrole products of haem metabolism, with nanomolar affinity. Using cryo-electron microscopy and X-ray crystallography, we mapped the tetrapyrrole interaction pocket to a deep cleft on the spike $\mathrm{N}$-terminal domain (NTD). At physiological concentrations, biliverdin significantly dampened the reactivity of SARS-CoV-2 spike with immune sera and inhibited a subset of neutralizing antibodies. Access to the tetrapyrrole-sensitive epitope is gated by a flexible loop on the distal face of the NTD. Accompanied by profound conformational changes in the NTD, antibody binding requires relocation of the gating loop, which folds into the cleft vacated by the metabolite. Our results indicate that SARS-CoV-2 spike NTD harbors a dominant epitope, access to which can be controlled by an allosteric mechanism that is regulated through the recruitment of a metabolite.

\section{INTRODUCTION}

Trimeric coronaviral spike glycoproteins form prominent features on viral particles that are responsible for the attachment to a receptor on the host cell and, ultimately, fusion of the viral and cellular membranes $(1,2)$. Encoded by a single viral gene, the mature spike glycoprotein comprises two subunits, S1 and S2, which mediate binding to the receptor and facilitate fusion, respectively. The recognition of the betacoronavirus SARS-CoV-2 host receptor, the cellular membrane protein angiotensin-converting enzyme 2 (ACE2), maps to the S1 C-terminal domain (referred to as the receptor binding domain, RBD) (3-5), while the function of the $\mathrm{N}$ terminal domain (NTD) remains enigmatic. The immune properties of the spike glycoprotein underpin ongoing SARSCoV-2 vaccine development efforts (6). Both S1 domains can be targeted by potent neutralizing antibodies that arise in infected individuals. Majority of the characterized neutralizing antibodies bind the $\mathrm{RBD}$, while minimal structural information exists about neutralizing epitopes on the NTD (7-11). Mutations within the SARS-CoV-2 spike NTD are associated with viral escape from antibody immunity (12$14)$ and have been observed in circulating viral strains $(15,16)$.

Here we show that the NTD of SARS-CoV-2 spike binds biliverdin with high affinity. The recruitment of the tetrapyrrole leads to stabilization of the NTD structure and makes the viral envelope glycoprotein refractory to neutralization by a subset of human antibodies. Using cryogenic electron microscopy (cryo-EM) and X-ray crystallography we dissect the mechanism of the competition between the metabolite and antibodies for binding to the spike.

\section{RESULTS}

SARS-CoV-2 and SARS-CoV-1 spike NTDs bind biliverdin and bilimbin

In the course of our activities to support the development of serology for SARS-CoV-2, we produced a range of 
recombinant coronaviral spike antigens by expression in human cell lines (fig. S1A). Surprisingly, preparations of SARSCoV-2 trimeric spike and S1 carried a distinctive green hue, with prominent peaks at $\sim 390$ and $670 \mathrm{~nm}$ in their light absorbance spectra (fig. S1A-B). These unusual features were also evident in the spectrum of S1 from SARS-CoV-1, another member of the sarbecovirus subgenus, but not those from the seasonal human coronaviruses NL63 and OC43 (fig. S1B-C). The property was confined within the spike NTD and absent in isolated RBD (fig. S1B). The spectra of the SARS-CoV spike constructs were consistent with biliverdin (fig. S1B), a product of haem metabolism responsible for the coloration of bruises and green jaundice. We isolated the pigment from denatured SARS-CoV-2 S1 and confirmed the presence of biliverdin IX $\alpha$ by mass spectrometry (fig. S2).

Haem is an essential prosthetic group in many proteins involved in processes requiring oxygen and/or electron transfer, such as cellular respiration (e.g. mitochondrial cytochrome c oxidase), oxygenation (P450 cytochromes), nitric oxide and peroxide metabolism (17). Because free haem is highly toxic, its cellular levels are tightly regulated through constitutive synthesis and catabolism. Biliverdin is produced at the first step of endogenous haem detoxification through the action of oxygenases and is then reduced to bilirubin, which is the final product of tetrapyrrole catabolism in humans. We measured tetrapyrrole binding to immobilized SARS-CoV-2 S1 using surface plasmon resonance (SPR) and estimated the dissociation constant $\left(\mathrm{K}_{\mathrm{d}}\right)$ for the interaction with biliverdin and bilirubin at $9.8 \pm 1.3 \mathrm{nM}$ and $720 \pm 250 \mathrm{nM}$, respectively (fig. S3A-B, Table S1). S1 bound haem considerably more weakly, with a $\mathrm{K}_{\mathrm{d}}$ of $7.0 \pm 1.2 \mu \mathrm{M}$, while no interaction was observed with protoporphyrin IX, the intact macrocyclic tetrapyrrole of haem (fig. S3C-D, Table S1).

\section{Structural basis for biliverdin recruitment by SARS- CoV-2 spike}

Next, we imaged single particles of the trimeric SARS-CoV-2 spike ectodomain $(3,18)$ in the presence of excess biliverdin using cryo-EM. Image processing resulted in the 3D reconstruction of closed (3RBDs-down) and partially open (1RBDup conformation) states of the spike at 3.35 and $3.50 \AA$ resolution, respectively (Fig. 1, fig. S4, Table S2). Close inspection of the cryo-EM maps revealed features interpretable as a biliverdin molecule buried within a deep cleft on one side of each of the NTD domains (Fig. 1, fig. S5A). To define the structural basis for the interaction more precisely, we co-crystallized the isolated NTD with biliverdin and determined the structure at $1.8 \AA$ resolution (Fig. 2, fig. S5B, Table S3). The metabolite fits snugly into the cleft with the pyrrole rings $B$ and $\mathrm{C}$ buried inside and propionate groups appended to rings A and D projecting toward the outside. The pocket is lined by hydrophobic residues (Ile101, Trp104, Ile119, Val126, Met177,
Phe192, Phe194, Ile203, and Leu226), which form van der Waals interactions with the ligand. Biliverdin packs against His207, which projects its $\mathrm{N}_{\varepsilon} 2$ atom toward pyrrolic amines, approaching three of them at $\sim 3.6$ A. Pyrroles A and B are involved in a $\pi-\pi$ stacking with side chain of Arg190, which is stabilized by hydrogen bonding with Asn99. The binding of biliverdin largely buries the side chain of Asn121, which makes a hydrogen bond with the lactam group of pyrrole D. In agreement with the extensive interactions observed in the crystal structure, the melting point of isolated NTD increased by over $8^{\circ} \mathrm{C}$ in the presence of biliverdin (fig. S3K). Unidentified entities at the tetrapyrrole binding site were observed in published SARS-CoV-2 spike reconstructions (1, 4, 18-22), presumably obtained with partial occupancy by the metabolite; in some cryo-EM maps, the bound biliverdin molecule is resolved remarkably well (fig. S6) (19-22).

We speculated that the protonation state of His207 in the biliverdin binding pocket (Fig. 2), and indeed of the tetrapyrrole itself, may affect the interaction. Concordantly, the $K_{d}$ of the S1-biliverdin interaction increased to $250 \pm 100$ $\mu \mathrm{M}$ at pH 5.0 (fig. S3E,H and Table S1), and purification under acidic conditions greatly reduced the biliverdin content of recombinant SARS-CoV-2 S1 (fig. S1D). Substitutions of spike residues closely involved in ligand binding (H207A, R190K and N121Q) diminished pigmentation of purified recombinant protein (fig. S1E). The biliverdin binding affinity of SARS-CoV-2 S1 was reduced by two and three orders of magnitude by the R190K and N121Q amino acid substitutions, respectively (fig. S3F-H, Table S1). The latter ablated the interaction with bilirubin, confirming that the tetrapyrroles share the binding site on the spike (fig. $\mathrm{S} 3 \mathrm{H}$ ). The residues corresponding to Asn121 and Arg190 appear to be strictly conserved across the entire sarbecovirus subgenus. By contrast, position 207 is variable, usually occupied by a tyrosine residue, as is the case in SARS-CoV-1 (fig. S7). Because SARS-CoV-1 S1 retained nanomolar affinity for biliver$\operatorname{din}\left(K_{d}=19.6 \pm 0.8 \mathrm{nM}\right.$; fig. S3I, Table S1), the tetrapyrrole binding may be a common property of all sarbecoviral spike glycoproteins.

\section{Biliverdin binding significantly downmodulates the reactivity of SARS-CoV-2 spike with immune sera}

SARS-CoV-2 spikes carrying R190K and N121Q mutations supported infection of Vero-ACE2 and Huh7-ACE2 cells by a pseudotyped lentiviral vector (fig. S8A). Moreover, infectivity of replication-competent SARS-CoV-2 was not affected by the presence of $100 \mu \mathrm{M}$ biliverdin (fig. S8B). Thus, the metabolite does not appear to play a critical role in viral entry under standard tissue culture conditions. Because biliverdin binding conceals a deep hydrophobic cleft on the NTD (Fig. 2), we suspected that it may mask or modify the antigenic properties of the viral spike. To test this hypothesis, we measured 
the reactivity of sera from 17 SARS-CoV-2-infected and convalescent individuals with full-length WT and N121Q SARSCoV-2 spike using a flow cytometry-based assay (23). Remarkably, addition of $10 \mu \mathrm{M}$ biliverdin reduced binding of patient IgGs to WT spike, reducing the reactivity of some of the immune sera by as much as $50 \%$ (with a median change of $31.4 \%$, ranging from $-10.4 \%$ to $-49.5 \%$ ) (Fig. 3). By contrast, antibody binding to N121Q SARS-CoV-2 spike was not affected by addition of biliverdin (median change $-2.0 \%$, range $+10.8 \%$ to $-12.9 \%$ ) (Fig. 3). Binding of IgM and IgA antibodies, which are present at lower titers in these patients (23), was more variably, but, statistically, not significantly affected (fig. S9B-D). In a separate experiment, we tested 91 clinical serum samples in an IgG capture enzyme-linked immunosorbent assay (ELISA). SARS-CoV-2 specific antibodies were detected using WT or N121Q S1 conjugated to horseradish peroxidase. Biliverdin-depleted WT S1 was significantly more reactive than the same protein supplemented with excess metabolite (fig. S10). By contrast, addition of biliverdin did not dampen detection of the SARS-CoV-2 antibodies with N121Q S1 (fig. S10).

\section{Identification of biliverdin-sensitive monoclonal anti- bodies to SARS-CoV-2 spike NTD}

It is remarkable that a small molecule with a footprint of 370 $\AA^{2}$, corresponding to less than $0.9 \%$ of solvent-exposed surface (per spike monomer, Fig. 1), competes with a considerable fraction of the spike-specific serum antibody population (Fig. 3). These results prompted us to evaluate a panel of human antibodies cloned from B cells of SARS-CoV-2 convalescent individuals. We used 38 IgGs reported in a recent study (11), as well as a panel of 15 novel SARS-CoV-2 S1-specific IgGs obtained from individuals with asymptomatic infection, or mild/severe disease undergoing characterization in one of our laboratories (14). We tested these monoclonal antibodies for binding to recombinant WT and N121Q S1 by ELISA. Remarkably, 9 of 53 (17\%) IgGs lost binding to WT, but not to N121Q S1, in the presence of $10 \mu \mathrm{M}$ biliverdin (Fig. 4A,C, fig. S11A). Furthermore, addition of biliverdin strongly suppressed binding of these antibodies to full-length WT but not N121Q SARS-CoV-2 spike expressed on the surface of transfected HEK293T cells (Fig. 4B,D). By contrast, reactivity of both RBD-specific controls (COVA1-18 and COVA1-12), was not affected by the metabolite (Fig. 4A-D). As expected, all biliverdin-sensitive antibodies recognize the NTD $(11,14)$.

Two of the biliverdin-sensitive monoclonal IgGs, COVA122 , COVA2-17, were previously reported to efficiently neutralize SARS-CoV-2 pseudotyped retrovirus (11). Addition of biliverdin suppressed neutralization of the pseudotype carrying WT but not N121Q spike (Fig. 4E). The mutation had a differential effect on neutralization showing a decrease in potency for COVA1-22 and no effect for P008_056 or COVA2-17. As expected, addition of biliverdin had no effect on neutralization by COVA1-18. Neutralization of replication-competent SARS-CoV-2 by P008_056, COVA1-22 or COVA2-17 was substantially decreased by addition of biliverdin (Fig. 4F). Intriguingly, while P008_056 seemed somewhat less potent in the pseudotype assay (Fig. 4E), it efficiently neutralized live SARS-CoV-2 virus, achieving $50 \%$ and $>90 \%$ inhibition at concentrations of 0.03 and $1.56 \mu \mathrm{g} / \mathrm{ml}$, respectively, in a biliverdin-sensitive manner (Fig. 4F, fig. S11B).

\section{Biliverdin inhibits antibody binding to SARS-CoV-2 spike NTD via an allosteric mechanism}

To establish the structural basis for SARS-CoV-2 neutralization by a biliverdin-sensitive antibody, we imaged single particles of the viral spike in complex with P008_056 antigen binding fragment (Fab). Cryo-EM image processing resulted in reconstruction of structures with one, two and three Fab moieties bound per trimeric viral glycoprotein (fig. S11A-B), and the best map was obtained for the complex containing a single Fab (Fig. $5 \mathrm{~A}$, fig. S12C-D). The reconstruction with a local resolution of $\sim 4 \AA$ at the NTD-Fab interface allowed for tracing of the protein backbone and revealed positions of key amino acid side chains (Fig. 5A, fig. S5C). P008_056 binds the spike at the side of the NTD $\beta$-sandwich fold, which undergoes profound conformational rearrangements (Movie S1). Access to the epitope is gated by a solvent-exposed loop composed of predominantly hydrophilic residues ("gate", SARS-CoV-2 spike residues 174188; Fig. 2). To allow P008_056 binding, the loop swings out of the way, with a backbone displacement in the middle of the loop of $\sim 15 \AA$ (Fig. 5B). The gating mechanism is accompanied by insertion of Phe175 and Met177, which are located in the beginning of the loop, into the hydrophobic pocket vacated by biliverdin (Fig. 5B, fig. S5C). Thus, when bound, the metabolite appears to act as a wedge that restricts gate opening. Antibody binding is additionally complemented by an upward movement of a $\beta$-hairpin ("lip", SARS-CoV-2 residues 143-155), which overlays a cluster of aromatic residues (Fig. 2, Fig. 5B). Both loop regions are variable, although the gate residues that replace biliverdin display considerable sequence conservation (consensus: ${ }^{175}[\mathrm{~F}, \mathrm{~L}] \mathrm{q}[\mathrm{L}, \mathrm{M}]^{177}$; fig. S7). The marked gain in thermal stability upon biliverdin binding (fig. S3K) is consistent with resistance to an antibody that requires major conformational remodeling of the NTD for binding (Movie S1).

\section{DISCUSSION}

Our data show that the NTD of SARS-CoV-2 harbors dominant epitope(s), responsible for a considerable fraction of spike antigenicity (Figs. 3 and 4). It is well-established that viruses employ extensive glycosylation of their envelopes to shield antibody epitopes from recognition by humoral immunity (24-26). Here, we propose a novel mode of immune evasion via allostery, regulated through recruitment of a 
metabolite. In contrast to glycosylation, co-opting a metabolite may allow conditional unmasking, for example under acidic conditions within the endosomal compartment. Of note, a recent study proposed $\mathrm{pH}$-dependent conformational masking of the epitopes on SARS-CoV-2 RBD (27).

Since the beginning of the COVID-19 pandemic, considerable effort was directed to monitoring the genetic changes within the virus. The biliverdin-binding cleft has remained intact in the dominant SARS-CoV-2 variants (such as B.1.1.7, B.1.351, and B.1.1.28). However, while this manuscript under review, R190S was reported in the emerging P.1 strain. It is currently unclear how widespread this mutation is, and it will be important to continue monitoring adaptation of the bat sarbecovirus to human host. Biliverdin levels in plasma of healthy individuals (0.9-6.9 $\mu \mathrm{M})$ and more so under pathological conditions $(>50 \mu \mathrm{M})(28)$ greatly exceed the $\mathrm{K}_{\mathrm{d}}$ of its interaction with the spike $(\sim 10 \mathrm{nM})$ and are therefore sufficient to impinge on SARS-CoV-2 antigenic properties and neutralization. Although SARS-CoV-2 spike bound bilirubin with lower affinity (fig. S3), this final product of haem catabolism accumulates at higher levels in vivo (28). Elevated bilirubin levels correlate with the symptoms and mortality among COVID-19 patients (29-32). Therefore, the tetrapyrroles may share a role in SARS-CoV-2 immune evasion. It is important to note that the binding of biliverdin and bilirubin to the spike is characterized by fast association and dissociation kinetics (fig. S3). The affinity of a typical antibody (10-200 pM) greatly exceeds that of the biliverdin-spike interaction (33). Accordingly, the metabolite is able to suppress antibody binding (Figs. 3 and 4), because it can reach considerably higher molar concentrations. In addition, tetrapyrrole levels are likely to vary between anatomical locations and during the course of natural infection, explaining the emergence of the biliverdin sensitive antibody fraction.

Severe COVID-19 symptoms and death are associated with neutrophil infiltration in pulmonary capillaries and alveolar space (34). Indeed, nasopharyngeal swabs of COVID-19 patients are enriched in neutrophil myeloperoxidase (35), a highly abundant haem-containing protein responsible for coloration of mucus (36). Incidentally, host mechanisms to minimize inflammation in viral infections include the activation of haem oxygenase 1 (37). Alongside extensive vascular damage, these symptoms provide rich source of haem catabolites, which may contribute to the inability to control the infection in severe cases. Although more work is required to validate this model, our results suggest that biliverdin binding may impair the sensitivity of SARS-CoV-2 immunoassays. Furthermore, it would be of interest to evaluate spike constructs deficient for the interaction with tetrapyrroles as vaccine candidates. Our results demonstrate a remarkable structural plasticity of the NTD and highlight the importance of this domain for antibody immunity against SARS-CoV-2.

\section{MATERIALS AND METHODS Protein expression and purification}

DNA fragments encoding SARS-CoV-2 S1 (Uniprot ID: P0DTC2; residues 1-530), NTD (1-310), RBD (319-541), SARSCoV-1 S1 (Uniprot ID: P59594; residues 1-518), HCoV NL63 (Uniprot ID: Q6Q1S2; residues 1-618), $\mathrm{HCoV}$ OC43 (isolate LRTI_238, NCBI accession code KX344031; residues 1-619) were codon-optimized for expression in human cells and cloned control of the cytomegalovirus promoter for production of the recombinant proteins carrying a C-terminal extension containing human rhinovirus $143 \mathrm{C}$ protease recognition site followed by a TwinStrep tag. The signal peptide from immunoglobulin kappa gene product (METDTLLLWVLLLWVPGSTGD) was used to direct secretion of the RBD construct. The vector for production of the His $_{6}$-tagged stabilized trimeric SARS-CoV-2 has been described (18). Expression constructs encoding heavy and light chains of P008_056 Fab were made by inserting the respective coding sequences into pHLsec (38), including a sequence encoding a hexa-histidine $\left(\mathrm{His}_{6}\right)$ tag on the heavy chain fragment $\mathrm{C}$ terminus.

With exception of trimeric stabilized SARS-CoV-2 spike ectodomain, the proteins were produced by transient transfection of Expi293 (Thermo Fisher Scientific) cells with endotoxin-free preparations of the corresponding DNA constructs using ExpiFectamine293 (Thermo Fisher Scientific). The cells were maintained in shake flasks in FreeStyle293 (Thermo Fisher Scientific) medium at $37^{\circ} \mathrm{C}$ in humidified $5 \% \mathrm{CO}_{2}$ atmosphere. To produce SARS-CoV-2 S1 NTD fragment for crystallography, cell culture medium was supplemented with 5 $\mu \mathrm{M}$ kifunensine (Sigma-Aldrich) to suppress complex glycosylation (39). Conditioned medium containing recombinant product was harvested twice, 4 and 8 days post-transfection, or once, for production of the NTD and P008_056 Fab, 5 days post-transfection. For production of the trimeric SARS-CoV2 spike ectodomain, Expi293 transfected with the pcDNA3based expression construct (18) were selected with $250 \mu \mathrm{g} / \mathrm{ml}$ geneticin. Stably transfected cells, grown to a density of 3.5 million per $\mathrm{ml}$ at $37^{\circ} \mathrm{C}$, were shifted to $32^{\circ} \mathrm{C}$ for 3 days prior to harvesting conditioned medium to enhance secretion of the viral glycoprotein $(40)$.

TwinStrep-tagged proteins were captured on Strep-Tactin XT (IBA LifeSciences) affinity resin. Following extensive washes in TBSE $(150 \mathrm{mM} \mathrm{NaCl}, 1 \mathrm{mM}$ ethylenediaminetetraacetic acid (EDTA), $25 \mathrm{mM}$ Tris- $\mathrm{HCl}, \mathrm{pH} 8.0$ ), the proteins were eluted in 1xBXT buffer (IBA LifeSciences). His 6 -tagged proteins were captured on HisTrap Excel (Sigma-Aldrich) resin and eluted with $300 \mathrm{mM}$ imidazole in phosphate buffered saline. For the use in crystallography, SARS-CoV-2 S1 NTD was digested with Endo Hf (New England Biolabs) and rhinoviral $3 \mathrm{C}$ protease to trim glycans and to remove the $\mathrm{C}$ terminal twin Strep tag; Endo Hf was depleted by absorption 
to amylose resin (New England Biolabs). The proteins were further purified by size exclusion chromatography through a Superdex 200 16/600 column (GE Healthcare) in HBSE (150 $\mathrm{mM} \mathrm{NaCl}, 1 \mathrm{mM}$ EDTA, $20 \mathrm{mM}$ Hepes-NaOH, pH 8.0) and concentrated by ultrafiltration using a Vivaspin-20 with 10$\mathrm{kDa}$ cut-off (Sartorius). To deplete biliverdin from SARS-CoV2 S1, recombinant protein eluted from Strep-Tactin XT resin was supplemented with $0.5 \mathrm{M}$ sodium acetate, $\mathrm{pH} 5.2$ and subjected to size exclusion chromatography through a Superdex 200 16/600 column in $200 \mathrm{mM}$ sodium acetate, pH 5.2; fractions containing S1 were pooled and dialyzed overnight against HBSE buffer. Light absorbance spectra of recombinant proteins were acquired using Jasco V-550 UV/VIS spectrophotometer.

\section{Mass spectrometry}

Recombinant SARS-CoV-2 S1 $(3.5 \mathrm{mg} / \mathrm{ml}, 500 \mu \mathrm{l})$, denatured by addition of $1 \%(\mathrm{w} / \mathrm{v})$ sodium dodecyl sulfate, was extracted with $500 \mu \mathrm{ln}$-butanol. Organic phase containing green pigment was allowed to evaporate under vacuum, and dry residue was re-dissolved in $20 \mu \mathrm{l}$ water. Liquid chromatographytandem mass spectrometry was performed as described previously (41). LC-MS/MS analysis was conducted using a Dionex UltiMate LC system (Thermo Scientific) with a ZICpHILIC column $(150 \mathrm{~mm} \times 4.6 \mathrm{~mm}, 5 \mu \mathrm{m}$ particle, Merck Sequant). A 15-min elution gradient of $80 \%$ Solvent A (20 mM ammonium carbonate in Optima HPLC grade water, SigmaAldrich) to $20 \%$ Solvent B (acetonitrile Optima HPLC grade, Sigma-Aldrich) was used, followed by a 5-min wash of 95:5 Solvent A to Solvent B and 5-min re-equilibration. Other parameters were as follows: flow rate, $300 \mu \mathrm{l} / \mathrm{min}$; column temperature, $25^{\circ} \mathrm{C}$; injection volume, $10 \mu \mathrm{l}$; autosampler temperature, $4^{\circ} \mathrm{C}$. Metabolites were detected across a mass range of 70-1050 m/z using a Q Exactive Orbitrap instrument (Thermo Scientific) with heated electrospray ionization and polarity switching mode at a resolution of 70,000 (at 200 $\mathrm{m} / \mathrm{z}$ ). MS parameters were as follows: spray voltage $3.5 \mathrm{kV}$ for positive mode and $3.2 \mathrm{kV}$ for negative mode; probe temperature, $320^{\circ} \mathrm{C}$; sheath gas, 30 arbitrary units; auxiliary gas, 5 arbitrary units. Parallel reaction monitoring was used at a resolution of 17,500 to confirm the identification of biliverdin; collision energy was set at 30 in high-energy collisional dissociation mode. Data was recorded using Xcalibur 3.0.63 software and analyzed using Free Style 1.6 and Tracefinder 4.1 software (Thermo Scientific) according to the manufacturer's workflows.

\section{SPR}

Experiments were performed on a Biacore S200 (Cytiva); S1 protein, diluted to $50 \mu \mathrm{g} / \mathrm{ml}$ in $10 \mathrm{mM}$ sodium acetate, $\mathrm{pH} 5.0$, was immobilized on a CM5 sensor chip (Cytiva product code BR100530) using amine coupling chemistry. Immobilization levels were typically 4,000 response units. Analyte binding was studied in running buffer comprising $150 \mathrm{mM} \mathrm{NaCl}, 50$ $\mathrm{mM}$ HEPES-NaOH, pH 8.0 or $50 \mathrm{mM}$ BisTris-HCl, pH 5.0, $0.05 \%$ Tween-20, and $1 \%$ dimethyl sulfoxide (DMSO). Biliverdin, bilirubin, haem, and protoporphyrin were obtained from Sigma-Aldrich (product codes 3089, 14370, 51280, and P8293, respectively). Generally, analyte stock solutions were prepared in DMSO prior to dilution in running buffer, maintaining the final DMSO concentration of $1 \%$. The final analyte concentration was verified by spectrophotometry, using the following molar extinction coefficients: biliverdin 39,900 (at a wavelength of $388 \mathrm{~nm})$, bilirubin $53,846(460 \mathrm{~nm})$, haem $58,440(385 \mathrm{~nm})$, and protoporphyrin IX 107,000 (407 nm). Alternatively, biliverdin, which is highly soluble at $\mathrm{pH}>7$, was dissolved directly in running buffer to omit DMSO from the experiment. The presence of DMSO did not affect the measured $K_{d}$ of the S1-biliverdin interaction (Table S1). All experiments were conducted using a CM5-kinetics-multicycle template at $25^{\circ} \mathrm{C}$. Flow rate was $30 \mu \mathrm{l} / \mathrm{min}$ with a contact time of $180 \mathrm{~s}$, followed by a dissociation time of $10 \mathrm{~min}$; three startups were performed at the beginning of each experiment. Solvent correction was deemed unnecessary for the assays that contained DMSO. Biliverdin displayed very fast association precluding detailed kinetics analyses due to mass transfer effects. Data were analyzed using the 1:1 binding model in the Biacore S200 Evaluation software to estimate equilibrium binding constants $\left(\mathrm{K}_{\mathrm{d}}\right)$.

\section{Protein thermostability assay}

Biliverdin-depleted SARS-CoV-2 NTD (corresponding to spike residues 1-310) was diluted to $1 \mathrm{mg} / \mathrm{ml}$ in $150 \mathrm{mM} \mathrm{NaCl}$, $20 \mathrm{mM}$ HEPES-NaOH, pH 8.0 and supplemented with biliverdin from a 5-mM stock prepared in $100 \mathrm{mM}$ Tris-HCl, pH8.0 where appropriate. Melting curves were recorded using $20-95^{\circ} \mathrm{C} 1.5^{\circ} \mathrm{C} / \mathrm{min}$ temperature ramps on a Promethius NT.48 instrument (Nanotemper). Melting points were determined from inflection points of fluorescence intensity ratios (350 and $330 \mathrm{~nm}$ ) using first derivative analysis (fig. S3K).

\section{Cryo-electron microscopy}

Four $\mu \mathrm{l}$ stabilized trimeric SARS-CoV-2 spike ectodomain (0.6 $\mathrm{mg} / \mathrm{ml}$ final concentration in TBSE supplemented with $0.1 \%$ n-octyl glucoside) with $25 \mu \mathrm{M}$ biliverdin or $0.2 \mathrm{mg} / \mathrm{ml}$ P008_056 Fab, was applied onto glow-discharged 200-mesh copper holey carbon R2/2 grids (Quantifoil) for $1 \mathrm{~min}$, under $100 \%$ humidity at $20^{\circ} \mathrm{C}$, before blotting for $3-4 \mathrm{~s}$ and plungefreezing in liquid ethane using Vitrobot Mark IV (Thermo Fisher Scientific). The data were collected on Titan Krios microscopes operating at $300 \mathrm{keV}$ (Thermo Fisher Scientific). Single particles of spike-biliverdin were imaged using a Falcon III direct electron detector (Thermo Fisher Scientific). A total of 15,962 movies were recorded with a calibrated pixel 
size of $1.09 \AA \AA$ and a total electron exposure of $33 \mathrm{e} / \AA^{2}$, spread over 30 frames in single electron counting mode. The spikeFab complex was imaged on a GIF Quantum K2 detector with a post-column energy filter (Gatan), selecting a $20-\mathrm{eV}$ window, in single electron counting mode. A total of 17,010 movies were collected with a pixel size of $1.38 \AA$ and total electron exposure of $51 \mathrm{e}-/ \AA^{2}$ spread over 40 frames. Both datasets were acquired with a defocus range of -1.6 to $-4 \mu \mathrm{m}$ (Table S2).

\section{Cryo-EM image processing and real-space refinement}

Micrograph movies were aligned with dose weighting applied using MotionCor2 (42), and the contrast transfer function (CTF) parameters were estimated from the frame sums with Gctf (43). Images exhibiting ice contamination or poor CTF estimation were discarded at this stage, leaving 15,803 (biliverdin complex) and 16,619 (Fab complex) movies for further processing. An initial set of particles, autopicked with Laplacian-of-Gaussian function in Relion-3.1 (44), was used to generate 2D class averages that served as templates for picking both datasets with Gautomatch (https://www.mrclmb.cam.ac.uk/kzhang/). Particles (1,209,334 and 2,505,265 for spike-biliverdin and spike-Fab, respectively) were extracted from weighted frame sums, binned 4-fold, and subjected to reference-free 2D classification in cryoSPARC-2 (45). 371,422 spike-biliverdin and 709,127 spike-Fab particles belonging to well-defined classes containing trimeric spike were selected for further processing (figs S4A, S11A). An initial 3D model was generated using $a b$ initio procedure in cryoSPARC2. Selected particles, re-extracted with 2-fold binning, were subjected to 3D classification into 11 (spike-biliverdin) and 16 (spike-Fab) classes in Relion-3.1. Particles belonging to selected 3D classes were re-extracted without binning and used in 3D reconstruction followed by CTF refinement (beam tilt and per-particle defocus) and Bayesian polishing in Relion-3.1. The final 3D reconstructions were done using non-uniform refinement procedure in cryoSPARC-2. Resolution is reported according to the gold-standard Fourier shell correlation (FSC), using the 0.143 criterion $(46,47)$ (figs S4C-D and S12C-D, Table S2). To aid in model building process, the maps were filtered and sharpened using deepEMhancer (48) or using density modification procedure in Phenix (49). An additional spike-Fab reconstruction was obtained using multibody refinement in Relion-3.1 accounting for two rigid bodies (one spanning the Fab moiety plus the associated NTD, and the second encompassing the rest of the structure) was used for illustration purposes (Fig. 4A).

For the 3RBD-down spike model, coordinates from protein databank entry 6ZGE (18) were docked into the cryo-EM map in Chimera (50). Residues 14-319 were replaced with the NTD crystal structure for each of the chains along with the associated biliverdin molecules. The model was manually adjusted in Coot (51) and refined using phenix.real_space_refine (version 1.19rc5-4047) (52). The model was then docked into the cryo-EM map of asymmetric 1RBD-up reconstruction and one RBD refitted to the extended position in Chimera; the model was manually adjusted in Coot and refined using phenix.real_space_refine. For the spike-Fab model, 3RBDdown spike model was fitted to the map using Chimera; the RBD of chain A was fitted in to the extended position, which is less well defined, and the NTD of chain C was extensively remodeled. The protein data bank was searched for similar structures using the sequence of the Fab chains; 6APC (53) and 6 PHB (54) were selected as templates for the heavy and light chains of the Fab respectively, variable and constant sub-domains were fitted individually using either phenix.dock_in_map (55) and/or fitted in Chimera. The Fab fragments were manually adjusted to match the sequence of P0008_056 antibody and fitted to the cryo-EM map. The constant domains of the Fab are less well resolved in the map and minimal adjustments were made to these domains. The whole structure was subjected to automatic flexible fitting using Namdinator v2.13 (56) and then phenix.real_space_refine before another round of manual rebuilding in Coot and a final round of phenix.real_space_refine. Biliverdin (BLA) ligand geometry definition file was generated by Grade (Global Phasing) and model quality was assessed using Molprobity (57).

\section{Crystal Structure of the NTD in complex with biliverdin} Protein construct (spanning SARS-CoV-2 S1 residues 1-310) at $10 \mathrm{mg} / \mathrm{ml}$ was supplemented with $90 \mu \mathrm{M}$ biliverdin before mixing with crystallization mother liquor in a 1:1 ratio. Platelike crystals grew to $80-120 \mu \mathrm{m}$ in two dimensions and $\sim 10-$ $20 \mu \mathrm{m}$ in the third dimension in conditions containing $24 \%$ PEG $3350(\mathrm{w} / \mathrm{v})$ and $0.25 \mathrm{M}$ NaSCN by hanging drop vapor diffusion over 1-2 weeks at $18^{\circ} \mathrm{C}$. Crystals were cryoprotected by the addition of PEG 400 to a final concentration of $30 \%$ $(\mathrm{v} / \mathrm{v})$ to the drop solution and frozen by plunging in liquid nitrogen. X-ray diffraction data were collected at the PX1 beamline, Swiss Light Source, using wavelength $1 \AA$, 100\% transmission, a $40-\mu \mathrm{m}$ beam, $0.1-\mathrm{s}$ exposure and $0.5^{\circ}$ rotation per image. Data were indexed, scaled and merged using XDS (58) and Aimless (59) via Xia2 (60). SARS-CoV-2 spike NTD (residues 14-290; PDB ID 6ZGE) (18) was used as a model for molecular replacement and yielded a solution containing one NTD per asymmetric unit, with a log likelihood gain of 490 and translation function Z-score of 22.7, in space group C222 using Phaser (61) within the Phenix package (55). The initial molecular replacement solution was subjected to morph model in Phenix before commencing with rounds of manual fitting in Coot (51) and refinement using phenix.refine (version 1.19rc4-4035) (55). First, the protein chain was fitted and extended where possible, and refined, then glycosylation 
moieties were added where visualized in the positive $F o-F c$ density, followed by conceivable PEG and water molecules. The electron density around the disulphide bonds suggested that they were labile and as such were modeled as alternative conformations between oxidized and reduced where appropriate and the occupancy refined between these states. The stability of the disulphide bonds could have been affected by trace amounts of DTT introduced during the treatment of the protein with $3 \mathrm{C}$ protease and EndoH. The $\mathrm{R}_{\text {free }}$ and $\mathrm{R}_{\text {work }}$ were 21.5 and $18.5 \%$, respectively, before a biliverdin molecule was fitted into the prominent positive difference density; rings A, $\mathrm{B}$ and $\mathrm{C}$ are defined very well in the density, ring $\mathrm{D}$ appears to be marginally less well defined. The final refinement included four Translation/Libration/Screw groups (residues 1467, 68-202, 203-278, 279-319) that had been segmented by the TLSMD server (62). Ligand geometry definitions were generated by Grade (Global Phasing). The final model consists of spike residues 14-319, one biliverdin molecule, seven N-linked glycans (attached to asparagine residues at positions 17, 61, 122, 149, 165, 234, and 282), 10 PEG moieties, and 351 water molecules and has reasonable geometry and fit to the electron density (Table S3, fig. S5B). Model quality was assessed using Molprobity (63). The alignment of the sarbecoviral spike sequences with the NTD secondary structures (fig. S7) was formatted using ESPript3 server (https://espript.ibcp.fr/ESPript/ESPript/) (64).

\section{Human sera}

Following written informed consent, serum samples from staff and patients of the Imperial College Healthcare NHS Trust (ICHNT) and the Wellington Hospital diagnosed with SARS-CoV-2 infection were donated to the Communicable Diseases Research Tissue Bank (CDRTB) of the Section of Virology, Department of Infectious Disease, Imperial College London. The use of these sera was approved by the CDRTB Steering Committee in accordance with the responsibility delegated by the National Research Ethics Service (South Central Ethics Committee Oxford - C, NRES references $15 / \mathrm{SC} / 0089$ and 20/SC/0226). The median time from onset of symptoms (or positive RT-PCR test in the case of asymptomatic infection) was 29 (0-94) days. Additionally, serum or plasma samples were obtained from University College London Hospitals (UCLH) COVID-19 patients testing positive for SARS-CoV-2 infection by RT-qPCR and sampled between March 2020 and April 2020 (23). The sera were collected a median of 21 (9-31) days post onset of symptoms. Patient sera were from residual samples prior to discarding, in accordance with Royal College Pathologists guidelines and the UCLH Clinical Governance for assay development and approved by HRA (IRAS reference 284088). All serum or plasma samples were heat-treated at $56^{\circ} \mathrm{C}$ for $30 \mathrm{~min}$ prior to testing by flow cytometry.

\section{IgG capture assay}

WT (depleted of biliverdin by chromatography under acidic conditions) and mutant SARS-CoV-2 S1 proteins $(4.1 \mathrm{mg} / \mathrm{ml}$; $100 \mu \mathrm{l}$ ) were conjugated to horseradish peroxidase (HRP) using the Lynx rapid HRP conjugation kit (BioRad). Following quenching and dilution in conjugate stabilizer (Clintech, Guildford, UK; product code \#MI20080), half of each conjugate was supplemented with $10 \mu \mathrm{M}$ biliverdin. Nunc 96 -well, U8 MaxiSorp plates (Fisher Scientific) were coated overnight at $4^{\circ} \mathrm{C}$ with AffiniPure rabbit anti-human IgG antibody (Stratech; product code \#309-005-008) diluted to $5 \mu \mathrm{g} / \mathrm{ml}$ in coating buffer (Clintech; product code \#643005). Following a 3-hours incubation at $37^{\circ} \mathrm{C}$, and a 1 hour incubation at room temperature, the wells were washed with washing buffer (Clintech; product code $\# 20024$ ) and incubated for 4 hours in blocking solution (Clintech; product code \#MI20011). The wells were air-dried and stored desiccated at $4^{\circ} \mathrm{C}$ until use. For ELISA, 100- $\mu$ l serum samples, each diluted 1:100 in diluent buffer (Clintech, product code \#2040), were added to the coated wells and incubated stationary at $37^{\circ} \mathrm{C}$ for 1 hour. To detect S1-specific IgGs, the wells were washed with washing buffer (Clintech) and aspirated to dryness, following which $100 \mu \mathrm{l}$ of S1-HRP fusion conjugate diluted in conjugate diluent (Clintech; product code \#100171) to a previously defined optimum concentration (1:1,500) were added and incubated for one hour at $37^{\circ} \mathrm{C}$. The wells were then washed as before and developed for $30 \mathrm{~min}$ at $37^{\circ} \mathrm{C}$ using tetramethylbenzidine substrate (Clintech; product code $\# 2030 \mathrm{~b}$ ), quenched by the addition of $50 \mu \mathrm{l}$ stop solution (Clintech; product code \#20031). The resulting optical densities (ODs) were acquired using a SpectraMax M2 reader (Molecular Devices).

The IgG capture ELISA data was modeled with a Bayesian linear model, using the gamma likelihood function: $\operatorname{Gamma}(\mu$, Scale). The linear model took the form of $\log (\mu)=$ intercept[Sample] + offset[Protein], where the intercept[Sample] term allows varying intercepts across samples (to account for the repeated measurements of each serum sample across conditions, assumed to be distributed as Gamma( $\mu_{\text {intercept }}$, sca$\left.\left.\mathrm{l}_{\text {intercept }}\right)\right)$, and the offset[Protein] term accounts for variation attributable to different protein coatings. Pairwise contrasts were drawn from the posterior distribution to construct credible intervals for the difference in OD values between different protein coatings. Priors: offset[Protein] Normal(-3,0.2), scale $\sim$ Exponential(5), $\mu_{\text {intercept }} \sim \operatorname{Normal}(1,0.2)$, scale $_{\text {intercept }} \sim \mathrm{Ex}-$ ponential(5). Monte Carlo settings: 10,000 iterations, 4 chains, adapt_delta $=0.95$, sampler $=$ NUTS .

\section{Flow cytometry}

Serum antibody binding to full-length SARS-CoV-2 S expressed on HEK293T cells was performed using a recently described method (23). Briefly, HEK293T cells were transfected with an expression vector (pcDNA3) carrying codon- 
optimized genes encoding either the wild-type SARS-CoV-2 S (UniProt ID: P0DTC2) or N121Q SARS-CoV-2 S, using GeneJuice (EMD Millipore). Two days after transfection, cells were trypsinized and transferred into V-bottom 96-well plates (20,000 cells/well). Cells were incubated with sera (diluted 1:50 in PBS) for $30 \mathrm{~min}$, with or without addition of 10 $\mu \mathrm{M}$ biliverdin throughout the staining period. They were then washed with FACS buffer (PBS, 5\% BSA, 0.05\% sodium azide) and stained with FITC anti-IgG (clone HP6017, Biolegend), APC anti-IgM (clone MHM-88, Biolegend) and PE anti-IgA (clone IS11-8E10, Miltenyi Biotech) for $30 \mathrm{~min}$ (all antibodies diluted 1:200 in FACS buffer). Samples were run on a Ze5 analyzer (Bio-Rad) running Bio-Rad Everest software v2.4 and analyzed using FlowJo v10 (Tree Star Inc.) analysis software. To calculate the effect of biliverdin, the mean fluorescence intensity (MFI) of positively stained cells only was used in each condition. The MFI data was modeled with a Bayesian linear model, using the gamma likelihood function: Gamma( $\mu$, Scale). The linear model took the form of $\log (\mu)=$ intercept[Sample] + offset[Protein], where the intercept[Sample] term allows varying intercepts across samples (to account for the repeated measurements of each serum sample across conditions, assumed to be distributed as $\left.\operatorname{Normal}\left(\mu_{\text {intercept }}, \sigma_{\text {intercept }}\right)\right)$, and the offset[Protein] term accounts for variation attributable to different protein coatings. Pairwise contrasts were drawn from the posterior distribution to construct credible intervals for the difference in MFI values between samples \pm biliverdin. Priors: offset[Protein] $\sim \operatorname{Normal}(0,400)$, scale $\sim \operatorname{Exponential}(0.1), \quad \mu_{\text {intercept }} \sim$ Nor$\operatorname{mal}(2500,200), \quad \sigma_{\text {intercept }} \sim \operatorname{Exponential}(0.01)$. Monte Carlo settings: 10,000 iterations, 4 chains, adapt_delta $=0.95$, sampler $=$ NUTS.

The same procedure was performed to assess monoclonal IgG binding to cell surface SARS-CoV-2 spike with the following alterations: Transfection was performed with PEI-Max (1 mg/ml, Polysciences), FACS wash buffer (FWB) containing PBS supplemented with $1 \%$ BSA. Monoclonal IgGs were serially diluted 10 -fold from $50 \mathrm{\mu g} / \mathrm{ml}$ prior to mixing with transfected cells. Antibody binding was detected with APC antiIgG (Biolegend) diluted 1:200 in FWB buffer. Samples were run on a NovoCyte 96 -well plate flow cytometer and analyzed using FlowJo v10 (Tree Star) analysis software. Three buffer only samples and secondary antibody alone conditions were used to define the spike-positive gate.

\section{Monoclonal human antibodies}

The following IgGs COVA1-26, COVA1-23, COVA2-38, COVA2-17, COVA1-20, COVA2-26, COVA1-22, COVA3-07, COVA2-03, COVA1-18,COVA1-12, COVA1-16, COVA2-01, COVA2-02, COVA204, COVA2-07, COVA2-11, COVA2-15, COVA2-29, COVA2-39, COVA2-44, COVA2-46, COVA2-10, COVA2-25, COVA2-30 have been reported (11). Cloning and characterization of human IgGs
P008_056, P003_027, P008_039, P008_051, P008_052, P003_014, P008_057, P008_100, P008_081, P008_017, P008_087, P054_021, P008_007, P003_055, and P008_108 is described elsewhere (14).

\section{ELISA with monoclonal IgGs}

The assays were performed in a similar manner to the previously described protocol for serum samples $(23,65,66)$. Briefly, high-binding ELISA plates (Corning, product code $3690)$ were coated with $3 \mu \mathrm{g} / \mathrm{ml}(25 \mu \mathrm{l}$ per well) SARS-CoV2 WT S1 antigen (purified with or without acid treatment) or $\mathrm{N} 121 \mathrm{Q}$ S1 in PBS, either overnight at $4{ }^{\circ} \mathrm{C}$ or for $2 \mathrm{~h}$ at $37^{\circ} \mathrm{C}$. Wells were washed with PBS supplemented with $0.05 \%$ Tween-20 (PBS-T) and blocked with $100 \mu \mathrm{l} 2 \%$ casein in PBS for $1 \mathrm{~h}$ at room temperature. The wells were emptied and $25 \mu \mathrm{l}$ of $2 \%(\mathrm{w} / \mathrm{v})$ casein in PBS was added per well. This solution was supplemented with biliverdin at $10 \mu \mathrm{M}$ where indicated. Serial dilutions of IgGs were prepared in separate 96 -well plate (Greiner Bio-One) in $2 \%$ casein, and then $25 \mu \mathrm{l}$ of each serial dilution added to the ELISA assay plates and incubated for $2 \mathrm{~h}$ at room temperature. Wells were washed with PBS-T. Secondary antibody was added and incubated for $1 \mathrm{~h}$ at room temperature. IgG binding was detected using goat-anti-human-Fc conjugated to alkaline phosphatase (1:1,000; Jackson, product code 109-055-098). Wells were washed with PBS-T, and alkaline phosphatase substrate (Sigma-Aldrich) was added and read at $405 \mathrm{~nm}$. Area under the curve values were calculated using GraphPad Prism.

\section{Pseudotype infectivity assay}

Simian immunodeficiency (SIV) particles were used to assess effects of H207A, R190K and N121Q mutations on the function of SARS-CoV-2 spike. HEK293T cells, seeded one day earlier in 10-cm dishes in complete Dulbecco's modified Eagle's medium (DMEM, supplemented with $10 \%$ (v/v) fetal bovine serum, FBS), were co-transfected with $17 \mu \mathrm{g}$ SIVMAC239GFP, an $e n v$ - and $n e f$ - defective provirus construct expressing a GFP reporter (67), and $4 \mu \mathrm{g}$ pcDNA-SARS-CoV-2-del19, encoding SARS-CoV-2 spike with or without mutations in the biliverdin binding pocket. To improve pseudotyping efficiency, the constructs encoded a truncation of the spike Cterminal 19 amino acid residues (68). Viral pseudotypes were harvested 48 hours post-transfection, clarified by low-speed centrifugation at $300 \times g$ for $5 \mathrm{~min}$ and filtered through a 0.45 $\mu \mathrm{m}$ filter. The stocks of viruses pseudotyped with the spike variants were diluted to an equal reverse transcriptase activity (69). Six 5-fold serially diluted virus stocks were inoculated in quadruplicate in 96-well plates onto Huh7 and Vero cells, modified to overexpress ACE2 from a lentiviral vector, seeded one day before infection in 96 -well plates. At 48 hours post-infection, fluorescent cells were counted using the Ensight plate reader (Perkin Elmer). Infectivity was calculated 
from values falling into a linear dilution range by dividing the number of infected cells in a well for the amount of reverse transcriptase activity associated to the virus inoculum, expressed in $\mathrm{mU}$.

\section{Pseudotype neutralization assay}

HIV-1 particles pseudotyped with SARS-Cov-2 spike were produced in a T75 flask seeded the day before with 3 million HEK293T/17 cells (American Type Culture Collection; catalog code CRL-11268) in $10 \mathrm{ml}$ complete DMEM, supplemented with $10 \%(\mathrm{v} / \mathrm{v}) \mathrm{FBS}, 100 \mathrm{IU} / \mathrm{ml}$ penicillin and $100 \mu \mathrm{g} / \mathrm{ml}$ streptomycin. Cells were transfected using $60 \mu \mathrm{g}$ of PEI-Max (Polysciences) with a mix of three plasmids: $9.1 \mu \mathrm{g}$ HIV-1 luciferase reporter vector (65), $9.1 \mu \mathrm{g}$ HIV-1 p8.91 packaging construct (70) and $1.4 \mu \mathrm{g}$ WT SARS-CoV-2 spike expression vector (23) or its N121Q mutant version. Supernatants containing pseudotyped virions were harvested $48 \mathrm{~h}$ posttransfection, filtered through a $0.45-\mu \mathrm{m}$ filter and stored at $80^{\circ} \mathrm{C}$. Neutralization assays were conducted by serial dilution of monoclonal IgGs at the indicated concentrations in DMEM (10\% (v/v) FBS and 1\% penicillin-streptomycin) and incubated with pseudotyped virus for $1 \mathrm{~h}$ at $37^{\circ} \mathrm{C}$ in 96 -well plates. HeLa cells stably expressing ACE-2 (provided by J.E. Voss, Scripps Institute) (71) were then added to the assay $(10,000$ cells per $100 \mu \mathrm{l}$ per well). After 48-72 h luminescence was assessed as a proxy of infection by lysing cells with the BrightGlo luciferase kit (Promega), using a Glomax plate reader (Promega). Measurements were performed in duplicate and used to calculate $50 \%$ inhibitory concentrations $\left(\mathrm{IC}_{50}\right)$ in GraphPad Prism software.

\section{SARS-CoV-2 infectivity assay}

SARS-CoV-2 strain BetaCoV/England/02/2020 (obtained from Public Health England) was propagated and quantified as described previously (72). VeroE6 cells were grown in DMEM (supplemented with $10 \% \mathrm{FBS}$ ) at $37^{\circ} \mathrm{C}$ and $5 \% \mathrm{CO}_{2}$ in 96-well imaging plates (Greiner \#655090). SARS-CoV-2 (0.5 plaque forming units per cell) was added to DMEM with 2 or $10 \%$ (v/v) FBS with or without $100 \mu \mathrm{M}$ biliverdin and added to the cells. At 22 hours post-infection, cells were fixed, permeabilized and stained for SARS-CoV-2 $\mathrm{N}$ protein using Alexa488-labeled CR3009 antibody (73) and 4' ,6-diamidino2-phenylindole (DAPI). The plate was imaged using the highcontent screening Opera Phenix microscope (Perkin Elmer) with a $5 \mathrm{x}$ lens. Harmony software (Perkin Elmer) was used to delineate the whole well area and to determine the total intensities of the Alexa488 (SARS-CoV-2 N protein) and DAPI (which stains DNA) signals per said whole well area during image acquisition. Background-subtracted Alexa488 intensities were normalized to the untreated control condition.

\section{SARS-CoV2 neutralization assay}

Vero E6 (Cercopithecus aethiops derived epithelial kidney cells, provided by Prof. Wendy Barclay, Imperial College London) cells were grown in DMEM, supplemented with GlutaMAX (Thermo Fisher Scientific), 10\% (v/v) FBS, and $20 \mu \mathrm{g} / \mathrm{ml}$ gentamicin, and incubated at $37^{\circ} \mathrm{C}$ in $5 \% \mathrm{CO}_{2}$ atmosphere. SARS-CoV-2 Strain England 2 (England 02/2020/407073) was obtained from Public Health England. The virus was propagated by infecting Vero E6 cells in T75 flasks (60-70\% confluent), at a multiplicity of infection 0.005 in $3 \mathrm{ml}$ of DMEM, supplemented with GlutaMAX and $10 \%$ (v/v) FBS. Cells were incubated for 1 hour at $37^{\circ} \mathrm{C}$ before adding $15 \mathrm{ml}$ of the same medium. Supernatant was harvested 72 hours post-infection following visible cytopathic effect, and filtered through a $0.22-\mu \mathrm{m}$ filter, aliquoted and stored at -80C. The infectious virus titer was determined by plaque assay in Vero E6 cells.

Neutralization assays were performed as previously described (65). Cells were seeded at a concentration of 20,000 cells/100 $\mu \mathrm{l}$ per well in 96 -well plates and allowed to adhere overnight. Serial dilutions of monoclonal antibodies were prepared with DMEM media (supplemented with $2 \%$ FBS, $100 \mathrm{IU} / \mathrm{ml}$ penicillin and $100 \mu \mathrm{g} / \mathrm{ml}$ streptomycin, Thermo Fisher Scientific) and incubated with SARS-CoV-2 for 1 hour at $37^{\circ} \mathrm{C}$. Biliverdin was added to the virus at a final concentration of $25 \mu \mathrm{M}$ before addition to the antibody. The media was removed from the pre-plated Vero-E6 cells and the serum-virus mixtures were added to the Vero E6 cells and incubated at $37^{\circ} \mathrm{C}$ for 24 hours. These virus/serum mixtures were aspirated and cells fixed with $150 \mu \mathrm{l}$ of $4 \%$ formaldehyde at room temperature for $30 \mathrm{~min}$ and then topped up to 300 $\mu \mathrm{l}$ with PBS. The cells were washed once with PBS and permeabilized with $0.1 \%$ Triton-X100 in PBS at room temperature for $15 \mathrm{~min}$. The cells were washed twice with PBS and blocked using 3\% milk in PBS at room temperature for 15 min. The blocking solution was removed cells were incubated with $2 \mu \mathrm{g} / \mathrm{ml}$ SARS-CoV-2 nuclear protein-specific murinizedCR3009 antibody in PBS supplemented with $1 \%$ milk at room temperature for $45 \mathrm{~min}$. The cells were washed twice with PBS and horse anti-mouse-IgG-conjugated to HRP was added (1:2,000 in 1\% milk in PBS, Cell Signaling Technology; product code S7076) at room temperature for $45 \mathrm{~min}$. The cells were washed twice with PBS, developed using 3,3',5,5' -tetramethylbenzidine substrate for 30 min and quenched using $2 \mathrm{M}$ sulfuric acid prior to reading at $450 \mathrm{~nm}$. Measurements were performed in duplicate.

\section{REFERENCES AND NOTES}

1. Z. Ke, J. Oton, K. Qu, M. Cortese, V. Zila, L. McKeane, T. Nakane, J. Zivanov, C. J. Neufeldt, B. Cerikan, J. M. Lu, J. Peukes, X. Xiong, H. G. Kräusslich, S. H. W. Scheres, R. Bartenschlager, J. A. G. Briggs, Structures and distributions of SARSCoV-2 spike proteins on intact virions. Nature 588, 498-502 (2020). doi:10.1038/s41586-020-2665-2 Medline

2. F. Li, Structure, Function, and Evolution of Coronavirus Spike Proteins. Annu. Rev. 
Virol. 3, 237-261 (2016). doi:10.1146/annurev-virology-110615-042301 Medline

3. D. Wrapp, N. Wang, K. S. Corbett, J. A. Goldsmith, C. L. Hsieh, O. Abiona, B. S. Graham, J. S. McLellan, Cryo-EM structure of the 2019-nCoV spike in the prefusion conformation. Science 367, 1260-1263 (2020) doi:10.1126/science.abb2507 Medline

4. A. C. Walls, Y. J. Park, M. A. Tortorici, A. Wall, A. T. McGuire, D. Veesler, Structure, Function, and Antigenicity of the SARS-CoV-2 Spike Glycoprotein. Cell 181, 281$292 \mathrm{e} 286$ (2020).

5. B. Ju, Q. Zhang, J. Ge, R. Wang, J. Sun, X. Ge, J. Yu, S. Shan, B. Zhou, S. Song, X Tang, J. Yu, J. Lan, J. Yuan, H. Wang, J. Zhao, S. Zhang, Y. Wang, X. Shi, L. Liu, J. Zhao, X. Wang, Z. Zhang, L. Zhang, Human neutralizing antibodies elicited by SARS-CoV-2 infection. Nature 584, 115-119 (2020). doi:10.1038/s41586-0202380-z Medline

6. J. S. Tregoning, E. S. Brown, H. M. Cheeseman, K. E. Flight, S. L. Higham, N. M. Lemm, B. F. Pierce, D. C. Stirling, Z. Wang, K. M. Pollock, Vaccines for COVID-19. Clin. Exp. Immunol. 202, 162-192 (2020). doi:10.1111/cei.13517 Medline

7. S. J. Zost, P. Gilchuk, J. B. Case, E. Binshtein, R. E. Chen, J. P. Nkolola, A. Schäfer, J. X. Reidy, A. Trivette, R. S. Nargi, R. E. Sutton, N. Suryadevara, D. R. Martinez, L. E. Williamson, E. C. Chen, T. Jones, S. Day, L. Myers, A. O. Hassan, N. M. Kafai, E. S. Winkler, J. M. Fox, S. Shrihari, B. K. Mueller, J. Meiler, A. Chandrashekar, N. B. Mercado, J. J. Steinhardt, K. Ren, Y. M. Loo, N. L. Kallewaard, B. T. McCune, S. P. Keeler, M. J. Holtzman, D. H. Barouch, L. E. Gralinski, R. S. Baric, L. B. Thackray, M. S. Diamond, R. H. Carnahan, J. E. Crowe Jr., Potently neutralizing and protective human antibodies against SARS-CoV-2. Nature 584, 443-449 (2020). doi:10.1038/s41586-020-2548-6 Medline

8. X. Chi, R. Yan, J. Zhang, G. Zhang, Y. Zhang, M. Hao, Z. Zhang, P. Fan, Y. Dong, Y. Yang, Z. Chen, Y. Guo, J. Zhang, Y. Li, X. Song, Y. Chen, L. Xia, L. Fu, L. Hou, J. Xu, C. Yu, J. Li, Q. Zhou, W. Chen, A neutralizing human antibody binds to the Nterminal domain of the Spike protein of SARS-CoV-2. Science 369, 650-655 (2020). doi:10.1126/science.abc6952 Medline

9. L. Liu, P. Wang, M. S. Nair, J. Yu, M. Rapp, Q. Wang, Y. Luo, J. F. Chan, V. Sahi, A. Figueroa, X. V. Guo, G. Cerutti, J. Bimela, J. Gorman, T. Zhou, Z. Chen, K. Y. Yuen, P. D. Kwong, J. G. Sodroski, M. T. Yin, Z. Sheng, Y. Huang, L. Shapiro, D. D. Ho, Potent neutralizing antibodies against multiple epitopes on SARS-CoV-2 spike. Nature 584, 450-456 (2020). doi:10.1038/s41586-020-2571-7 Medline

10. C. O. Barnes, C. A. Jette, M. E. Abernathy, K. A. Dam, S. R. Esswein, H. B. Gristick, A. G. Malyutin, N. G. Sharaf, K. E. Huey-Tubman, Y. E. Lee, D. F. Robbiani, M. C. Nussenzweig, A. P. West Jr., P. J. Bjorkman, SARS-CoV-2 neutralizing antibody structures inform therapeutic strategies. Nature 588, 682-687 (2020). doi:10.1038/s41586-020-2852-1 Medline

11. P. J. M. Brouwer, T. G. Caniels, K. van der Straten, J. L. Snitselaar, Y. Aldon, S. Bangaru, J. L. Torres, N. M. A. Okba, M. Claireaux, G. Kerster, A. E. H. Bentlage, M. M. van Haaren, D. Guerra, J. A. Burger, E. E. Schermer, K. D. Verheul, N. van der Velde, A. van der Kooi, J. van Schooten, M. J. van Breemen, T. P. L. Bijl, K. Sliepen, A. Aartse, R. Derking, I. Bontjer, N. A. Kootstra, W. J. Wiersinga, G. Vidarsson, B. L. Haagmans, A. B. Ward, G. J. de Bree, R. W. Sanders, M. J. van Gils, Potent neutralizing antibodies from COVID-19 patients define multiple targets of vulnerability. Science 369, 643-650 (2020). doi:10.1126/science.abc5902 Medline

12. E. Andreano, G. Piccini, D. Licastro, L. Casalino, N. V. Johnson, I. Paciello, S. D. Monego, E. Pantano, N. Manganaro, A. Manenti, R. Manna, E. Casa, I. Hyseni, L. Benincasa, E. Montomoli, R. E. Amaro, J. S. McLellan, R. Rappuoli, SARS-CoV-2 escape in vitro from a highly neutralizing COVID-19 convalescent plasma. bioRxiv, 2020.2012.2028.424451 (2020).

13. S. A. Kemp, D. A. Collier, R. P. Datir, I. Ferreira, S. Gayed, A. Jahun, M. Hosmillo, C. Rees-Spear, P. Mlcochova, I. U. Lumb, D. J. Roberts, A. Chandra, N. Temperton, C.-N. B. C.-. Collaboration, C.-G. U. Consortium, K. Sharrocks, E. Blane, Y. Modis, K. E. Leigh, J. A. G. Briggs, M. J. van Gils, K. G. C. Smith, J. R. Bradley, C. Smith, R. Doffinger, L. Ceron-Gutierrez, G. Barcenas-Morales, D. D. Pollock, R. A. Goldstein, A. Smielewska, J. P. Skittrall, T. Gouliouris, I. G. Goodfellow, E. Gkrania-Klotsas, C. J. R. Illingworth, L. E. McCoy, R. K. Gupta, SARS-CoV-2 evolution during treatment of chronic infection. Nature 592, 277-282 (2021). doi.org/10.1038/s41586-02103291-y

14. C. Graham, J. Seow, I. Huettner, H. Khan, N. Kouphou, S. Acors, H. Winstone, S. Pickering, R. P. Galao, M. J. Lista, J. M. Jimenez-Guardeno, A. G. Laing, Y. Wu, M.
Joseph, L. Muir, W. M. Ng, H. M. E. Duyvesteyn, Y. Zhao, T. A. Bowden, M. ShankarHari, A. Rosa, P. Cherepanov, L. E. McCoy, A. C. Hayday, S. J.D. Neil, M. H. Malim, K. J. Doores, Impact of the B.1.1.7 variant on neutralizing monoclonal antibodies recognizing diverse epitopes on SARS-CoV-2 Spike. bioRxiv https://www.biorxiv.org/content/10.1101/2021.02.03.429355v1 (2021).

15. A. Rambaut et al., Preliminary genomic characterisation of an emergent SARSCoV-2 lineage in the UK defined by a novel set of spike mutations. https://virological.org/t/preliminary-genomic-characterisation-of-anemergent-sars-cov-2-lineage-in-the-uk-defined-by-a-novel-set-of-spikemutations/563 (2021).

16. H. Tegally, E. Wilkinson, R. J. Lessells, J. Giandhari, S. Pillay, N. Msomi, K. Mlisana, J. N. Bhiman, A. von Gottberg, S. Walaza, V. Fonseca, M. Allam, A. Ismail, A. J. Glass, S. Engelbrecht, G. Van Zyl, W. Preiser, C. Williamson, F. Petruccione, A. Sigal, I. Gazy, D. Hardie, N. Y. Hsiao, D. Martin, D. York, D. Goedhals, E. J. San, M. Giovanetti, J. Lourenço, L. C. J. Alcantara, T. de Oliveira, Sixteen novel lineages of SARS-CoV-2 in South Africa. Nat. Med. 27, 440-446 (2021). doi:10.1038/s41591021-01255-3 Medline

17. A. W. Munro, H. M. Girvan, K. J. McLean, M. R. Cheesman, D. Leys, in Tetrapyrroles: Birth, Life and Death, M. J. Warren, A. G. Smith, Eds. (Springer New York, New York, NY, 2009), pp. 160-183.

18. A. G. Wrobel, D. J. Benton, P. Xu, C. Roustan, S. R. Martin, P. B. Rosenthal, J. J. Skehel, S. J. Gamblin, SARS-CoV-2 and bat RaTG13 spike glycoprotein structures inform on virus evolution and furin-cleavage effects. Nat. Struct. Mol. Biol. 27, 763-767 (2020). doi:10.1038/s41594-020-0468-7 Medline

19. C. Xu, Y. Wang, C. Liu, C. Zhang, W. Han, X. Hong, Y. Wang, Q. Hong, S. Wang, Q. Zhao, Y. Wang, Y. Yang, K. Chen, W. Zheng, L. Kong, F. Wang, Q. Zuo, Z. Huang, Y. Cong, Conformational dynamics of SARS-CoV-2 trimeric spike glycoprotein in complex with receptor ACE2 revealed by cryo-EM. Sci. Adv. 7, eabe5575 (2021). Medline

20. M. A. Tortorici, M. Beltramello, F. A. Lempp, D. Pinto, H. V. Dang, L. E. Rosen, M. McCallum, J. Bowen, A. Minola, S. Jaconi, F. Zatta, A. De Marco, B. Guarino, S. Bianchi, E. J. Lauron, H. Tucker, J. Zhou, A. Peter, C. Havenar-Daughton, J. A. Wojcechowskyj, J. B. Case, R. E. Chen, H. Kaiser, M. Montiel-Ruiz, M. Meury, N. Czudnochowski, R. Spreafico, J. Dillen, C. Ng, N. Sprugasci, K. Culap, F. Benigni, R. Abdelnabi, S. C. Foo, M. A. Schmid, E. Cameroni, A. Riva, A. Gabrieli, M. Galli, M. S. Pizzuto, J. Neyts, M. S. Diamond, H. W. Virgin, G. Snell, D. Corti, K. Fink, D. Veesler, Ultrapotent human antibodies protect against SARS-CoV-2 challenge via multiple mechanisms. Science 370, 950-957 (2020). doi:10.1126/science.abe3354 Medline

21. L. Hanke, L. Vidakovics Perez, D. J. Sheward, H. Das, T. Schulte, A. Moliner-Morro, M. Corcoran, A. Achour, G. B. Karlsson Hedestam, B. M. Hällberg, B. Murrell, G. M. McInerney, An alpaca nanobody neutralizes SARS-CoV-2 by blocking receptor interaction. Nat. Commun. 11, 4420 (2020). doi:10.1038/s41467-020-18174-5 Medline

22. X. Xiong, K. Qu, K. A. Ciazynska, M. Hosmillo, A. P. Carter, S. Ebrahimi, Z. Ke, S. H. W. Scheres, L. Bergamaschi, G. L. Grice, Y. Zhang, J. A. Nathan, S. Baker, L. C. James, H. E. Baxendale, I. Goodfellow, R. Doffinger, J. A. G. Briggs; CITIID-NIHR COVID-19 BioResource Collaboration, A thermostable, closed SARS-CoV-2 spike protein trimer. Nat. Struct. Mol. Biol. 27, 934-941 (2020). doi:10.1038/s41594020-0478-5 Medline

23. K. W. Ng, N. Faulkner, G. H. Cornish, A. Rosa, R. Harvey, S. Hussain, R. Ulferts, C. Earl, A. G. Wrobel, D. J. Benton, C. Roustan, W. Bolland, R. Thompson, A. AguaDoce, P. Hobson, J. Heaney, H. Rickman, S. Paraskevopoulou, C. F. Houlihan, K. Thomson, E. Sanchez, G. Y. Shin, M. J. Spyer, D. Joshi, N. O'Reilly, P. A. Walker, S. Kjaer, A. Riddell, C. Moore, B. R. Jebson, M. Wilkinson, L. R. Marshall, E. C. Rosser, A. Radziszewska, H. Peckham, C. Ciurtin, L. R. Wedderburn, R. Beale, C. Swanton, S. Gandhi, B. Stockinger, J. McCauley, S. J. Gamblin, L. E. McCoy, P. Cherepanov, E. Nastouli, G. Kassiotis, Preexisting and de novo humoral immunity to SARS-CoV2 in humans. Science 370, 1339-1343 (2020). doi:10.1126/science.abe1107 Medline

24. L. E. McCoy, M. J. van Gils, G. Ozorowski, T. Messmer, B. Briney, J. E. Voss, D. W. Kulp, M. S. Macauley, D. Sok, M. Pauthner, S. Menis, C. A. Cottrell, J. L. Torres, J. Hsueh, W. R. Schief, I. A. Wilson, A. B. Ward, R. W. Sanders, D. R. Burton, Holes in the Glycan Shield of the Native HIV Envelope Are a Target of Trimer-Elicited Neutralizing Antibodies. Cell Rep. 16, 2327-2338 (2016) 
doi:10.1016/i.celrep.2016.07.074 Medline

25. X. Wei, J. M. Decker, S. Wang, H. Hui, J. C. Kappes, X. Wu, J. F. Salazar-Gonzalez, M. G. Salazar, J. M. Kilby, M. S. Saag, N. L. Komarova, M. A. Nowak, B. H. Hahn, P. D. Kwong, G. M. Shaw, Antibody neutralization and escape by HIV-1. Nature $\mathbf{4 2 2}$, 307-312 (2003). doi:10.1038/nature01470 Medline

26. M. Crispin, A. B. Ward, I. A. Wilson, Structure and Immune Recognition of the HIV Glycan Shield. Annu. Rev. Biophys. 47, 499-523 (2018). doi:10.1146/annurevbiophys-060414-034156 Medline

27. T. Zhou, Y. Tsybovsky, J. Gorman, M. Rapp, G. Cerutti, G. Y. Chuang, P. S. Katsamba, J. M. Sampson, A. Schon, J. Bimela, J. C. Boyington, A. Nazzari, A. S. Olia, W. Shi, M. Sastry, T. Stephens, J. Stuckey, I. T. Teng, P. Wang, S. Wang, B. Zhang, R. A. Friesner, D. D. Ho, J. R. Mascola, L. Shapiro, P. D. Kwong, Cryo-EM Structures of SARS-CoV-2 Spike without and with ACE2 Reveal a pH-Dependent Switch to Mediate Endosomal Positioning of Receptor-Binding Domains. Cell Host Microbe 28, 867-879 e865 (2020).

28. M. Gåfvels, P. Holmström, A. Somell, F. Sjövall, J. O. Svensson, L. Ståhle, U. Broomé, P. Stål, A novel mutation in the biliverdin reductase-A gene combined with liver cirrhosis results in hyperbiliverdinaemia (green jaundice). Liver Int. 29, 1116-1124 (2009). doi:10.1111/j.1478-3231.2009.02029.x Medline

29. Z. Liu, J. Li, W. Long, W. Zeng, R. Gao, G. Zeng, D. Chen, S. Wang, Q. Li, D. Hu, L. Guo, Z. Li, X. Wu, Bilirubin Levels as Potential Indicators of Disease Severity in Coronavirus Disease Patients: A Retrospective Cohort Study. Front. Med. 7, 598870 (2020). doi:10.3389/fmed.2020.598870 Medline

30. P. Paliogiannis, A. Zinellu, Bilirubin levels in patients with mild and severe Covid19: A pooled analysis. Liver Int. 40, 1787-1788 (2020). doi:10.1111/liv.14477 Medline

31. M. A. Hundt, Y. Deng, M. M. Ciarleglio, M. H. Nathanson, J. K. Lim, Abnormal Liver Tests in COVID-19: A Retrospective Observational Cohort Study of 1,827 Patients in a Major U.S. Hospital Network. Hepatology 72, 1169-1176 (2020). doi:10.1002/hep.31487 Medline

32. T. Chen, D. Wu, H. Chen, W. Yan, D. Yang, G. Chen, K. Ma, D. Xu, H. Yu, H. Wang, T. Wang, W. Guo, J. Chen, C. Ding, X. Zhang, J. Huang, M. Han, S. Li, X. Luo, J. Zhao, Q. Ning, Clinical characteristics of 113 deceased patients with coronavirus disease 2019: Retrospective study. BMJ 368, m1091 (2020). doi:10.1136/bmi.m1091 Medline

33. J. P. Landry, Y. Ke, G. L. Yu, X. D. Zhu, Measuring affinity constants of 1450 monoclonal antibodies to peptide targets with a microarray-based label-free assay platform. J. Immunol. Methods 417, 86-96 (2015). doi:10.1016/i.jim.2014.12.011 Medline

34. J. Wang, Q. Li, Y. Yin, Y. Zhang, Y. Cao, X. Lin, L. Huang, D. Hoffmann, M. Lu, Y. Qiu, Excessive Neutrophils and Neutrophil Extracellular Traps in COVID-19. Front. Immunol. 11, 2063 (2020). doi:10.3389/fimmu.2020.02063 Medline

35. E. Akgun, M. B. Tuzuner, B. Sahin, M. Kilercik, C. Kulah, H. N. Cakiroglu, M. Serteser, I. Unsal, A. T. Baykal, Proteins associated with neutrophil degranulation are upregulated in nasopharyngeal swabs from SARS-CoV-2 patients. PLOS ONE 15, e0240012 (2020). doi:10.1371/journal.pone.0240012 Medline

36. J. Schultz, K. Kaminker, Myeloperoxidase of the leucocyte of normal human blood. I. Content and localization. Arch. Biochem. Biophys. 96, 465-467 (1962). doi:10.1016/0003-9861(62)90321-1 Medline

37. F. A. D. T. G. Wagener, P. Pickkers, S. J. Peterson, S. Immenschuh, N. G. Abraham, Targeting the Heme-Heme Oxygenase System to Prevent Severe Complications Following COVID-19 Infections. Antioxidants 9, 540 (2020). doi:10.3390/antiox9060540 Medline

38. A. R. Aricescu, W. Lu, E. Y. Jones, A time- and cost-efficient system for high-level protein production in mammalian cells. Acta Crystallogr. D Biol. Crystallogr. 62, 1243-1250 (2006). doi:10.1107/S0907444906029799 Medline

39. V. T. Chang, M. Crispin, A. R. Aricescu, D. J. Harvey, J. E. Nettleship, J. A. Fennelly, C. Yu, K. S. Boles, E. J. Evans, D. I. Stuart, R. A. Dwek, E. Y. Jones, R. J. Owens, S. J. Davis, Glycoprotein structural genomics: Solving the glycosylation problem. Structure 15, 267-273 (2007). doi:10.1016/i.str.2007.01.011 Medline

40. D. Esposito, J. Mehalko, M. Drew, K. Snead, V. Wall, T. Taylor, P. Frank, J. P. Denson, M. Hong, G. Gulten, K. Sadtler, S. Messing, W. Gillette, Optimizing highyield production of SARS-CoV-2 soluble spike trimers for serology assays. Protein Expr. Purif. 174, 105686 (2020). doi:10.1016/i.pep.2020.105686 Medline

41. L. Fets, P. C. Driscoll, F. Grimm, A. Jain, P. M. Nunes, M. Gounis, G. Doglioni, G.
Papageorgiou, T. J. Ragan, S. Campos, M. Silva Dos Santos, J. I. MacRae, N. O'Reilly, A. J. Wright, C. H. Benes, K. D. Courtney, D. House, D. Anastasiou, MCT2 mediates concentration-dependent inhibition of glutamine metabolism by MOG. Nat. Chem. Biol. 14, 1032-1042 (2018). doi:10.1038/s41589-018-0136-y Medline 42. S. Q. Zheng, E. Palovcak, J. P. Armache, K. A. Verba, Y. Cheng, D. A. Agard, MotionCor2: Anisotropic correction of beam-induced motion for improved cryoelectron microscopy. Nat. Methods 14, 331-332 (2017). doi:10.1038/nmeth.4193 Medline

43. K. Zhang, Gctf: Real-time CTF determination and correction. J. Struct. Biol. 193, 1-12 (2016). doi:10.1016/j.jsb.2015.11.003 Medline

44. S. H. W. Scheres, Amyloid structure determination in RELION-3.1. Acta Crystallogr. D Struct. Biol. 76, 94-101 (2020). doi:10.1107/S2059798319016577 Medline

45. A. Punjani, J. L. Rubinstein, D. J. Fleet, M. A. Brubaker, cryoSPARC: Algorithms for rapid unsupervised cryo-EM structure determination. Nat. Methods 14, 290-296 (2017). doi:10.1038/nmeth.4169 Medline

46. P. B. Rosenthal, R. Henderson, Optimal determination of particle orientation, absolute hand, and contrast loss in single-particle electron cryomicroscopy. J. Mol. Biol. 333, 721-745 (2003). doi:10.1016/i.jmb.2003.07.013 Medline

47. S. H. Scheres, S. Chen, Prevention of overfitting in cryo-EM structure determination. Nat. Methods 9, 853-854 (2012). doi:10.1038/nmeth.2115 Medline

48. R. Sanchez-Garcia, J. Gomez-Blanco, E. Cuervo, J. M. Carazo, C. O. S. Sorzano, J. Vargas, DeepEMhancer: A deep learning solution for cryo-EM volume postprocessing. bioRxiv (2020). 10.1101/2020.1106.1112.148296

49. T. C. Terwilliger, S. J. Ludtke, R. J. Read, P. D. Adams, P. V. Afonine, Improvement of cryo-EM maps by density modification. Nat. Methods 17, 923-927 (2020). doi:10.1038/s41592-020-0914-9 Medline

50. E. F. Pettersen, T. D. Goddard, C. C. Huang, G. S. Couch, D. M. Greenblatt, E. C. Meng, T. E. Ferrin, UCSF Chimera-A visualization system for exploratory research and analysis. J. Comput. Chem. 25, 1605-1612 (2004). doi:10.1002/jcc.20084 Medline

51. P. Emsley, K. Cowtan, Coot: Model-building tools for molecular graphics. Acta Crystallogr. D Biol. Crystallogr. 60, 2126-2132 (2004). doi:10.1107/S0907444904019158 Medline

52. P. V. Afonine, B. K. Poon, R. J. Read, O. V. Sobolev, T. C. Terwilliger, A. Urzhumtsev, P. D. Adams, Real-space refinement in PHENIX for cryo-EM and crystallography Acta Crystallogr. D Struct. Biol. 74, 531-544 (2018) doi:10.1107/S2059798318006551 Medline

53. E. Goodwin, M. S. A. Gilman, D. Wrapp, M. Chen, J. O. Ngwuta, S. M. Moin, P. Bai, A. Sivasubramanian, R. I. Connor, P. F. Wright, B. S. Graham, J. S. McLellan, L. M. Walker, Infants Infected with Respiratory Syncytial Virus Generate Potent Neutralizing Antibodies that Lack Somatic Hypermutation. Immunity. 48, 339349 (2018). doi:10.1016/i.immuni.2018.01.005

54. B. McLeod, K. Miura, S. W. Scally, A. Bosch, N. Nguyen, H. Shin, D. Kim, W. Volkmuth, S. Rämisch, J. A. Chichester, S. Streatfield, C. Woods, W. R. Schief, D. Emerling, C. R. King, J. P. Julien, Potent antibody lineage against malaria transmission elicited by human vaccination with Pfs25. Nat. Commun. 10, 4328 (2019). doi:10.1038/s41467-019-11980-6 Medline

55. P. D. Adams, R. W. Grosse-Kunstleve, L. W. Hung, T. R. loerger, A. J. McCoy, N. W. Moriarty, R. J. Read, J. C. Sacchettini, N. K. Sauter, T. C. Terwilliger, PHENIX: Building new software for automated crystallographic structure determination. Acta Crystallogr. D Biol. Crystallogr. 58, 1948-1954 (2002). doi:10.1107/S0907444902016657 Medline

56. R. T. Kidmose, J. Juhl, P. Nissen, T. Boesen, J. L. Karlsen, B. P. Pedersen, Namdinator - automatic molecular dynamics flexible fitting of structural models into cryo-EM and crystallography experimental maps. IUCrJ 6, 526-531 (2019). doi:10.1107/S2052252519007619 Medline

57. C. J. Williams, J. J. Headd, N. W. Moriarty, M. G. Prisant, L. L. Videau, L. N. Deis, V. Verma, D. A. Keedy, B. J. Hintze, V. B. Chen, S. Jain, S. M. Lewis, W. B. Arendall 3rd, J. Snoeyink, P. D. Adams, S. C. Lovell, J. S. Richardson, D. C. Richardson, MolProbity: More and better reference data for improved all-atom structure validation. Protein Sci. 27, 293-315 (2017). doi:10.1002/pro.3330 Medline

58. W. Kabsch, Xds. Acta Crystallogr. D Biol. Crystallogr. 66, 125-132 (2010). doi:10.1107/S0907444909047337 Medline

59. P. R. Evans, G. N. Murshudov, How good are my data and what is the resolution? 
Acta Crystallogr. D Biol. Crystallogr. 69, 1204-1214 (2013). doi:10.1107/S0907444913000061 Medline

60. G. Winter, C. M. Lobley, S. M. Prince, Decision making in xia2. Acta Crystallogr. D Biol. Crystallogr. 69, 1260-1273 (2013). doi:10.1107/S0907444913015308 Medline

61. A. J. McCoy, R. W. Grosse-Kunstleve, P. D. Adams, M. D. Winn, L. C. Storoni, R. J. Read, Phaser crystallographic software. J. Appl. Cryst. 40, 658-674 (2007) doi:10.1107/S0021889807021206 Medline

62. F. Zucker, P. C. Champ, E. A. Merritt, Validation of crystallographic models containing TLS or other descriptions of anisotropy. Acta Crystallogr. D Biol. Crystallogr. 66, 889-900 (2010). doi:10.1107/S0907444910020421 Medline

63. V. B. Chen, W. B. Arendall 3rd, J. J. Headd, D. A. Keedy, R. M. Immormino, G. J. Kapral, L. W. Murray, J. S. Richardson, D. C. Richardson, MolProbity: All-atom structure validation for macromolecular crystallography. Acta Crystallogr. D Biol. Crystallogr. 66, 12-21 (2010). doi:10.1107/S0907444909042073 Medline

64. X. Robert, P. Gouet, Deciphering key features in protein structures with the new ENDscript server. Nucleic Acids Res. 42 (W1), W320-4 (2014). doi:10.1093/nar/gku316 Medline

65. J. Seow, C. Graham, B. Merrick, S. Acors, S. Pickering, K. J. A. Steel, O. Hemmings, A. O'Byrne, N. Kouphou, R. P. Galao, G. Betancor, H. D. Wilson, A. W. Signell, H. Winstone, C. Kerridge, I. Huettner, J. M. Jimenez-Guardeño, M. J. Lista, N. Temperton, L. B. Snell, K. Bisnauthsing, A. Moore, A. Green, L. Martinez, B. Stokes, J. Honey, A. Izquierdo-Barras, G. Arbane, A. Patel, M. K. I. Tan, L. O'Connell, G. O'Hara, E. MacMahon, S. Douthwaite, G. Nebbia, R. Batra, R. Martinez-Nunez, M. Shankar-Hari, J. D. Edgeworth, S. J. D. Neil, M. H. Malim, K. J. Doores, Longitudinal observation and decline of neutralizing antibody responses in the three months following SARS-CoV-2 infection in humans. Nat. Microbiol. 5, 1598-1607 (2020). doi:10.1038/s41564-020-00813-8 Medline

66. S. Pickering, G. Betancor, R. P. Galão, B. Merrick, A. W. Signell, H. D. Wilson, M. T. Kia Ik, J. Seow, C. Graham, S. Acors, N. Kouphou, K. J. A. Steel, O. Hemmings, A. Patel, G. Nebbia, S. Douthwaite, L. O'Connell, J. Luptak, L. E. McCoy, P. Brouwer, M. J. van Gils, R. W. Sanders, R. Martinez Nunez, K. Bisnauthsing, G. O'Hara, E. MacMahon, R. Batra, M. H. Malim, S. J. D. Neil, K. J. Doores, J. D. Edgeworth, Comparative assessment of multiple COVID-19 serological technologies supports continued evaluation of point-of-care lateral flow assays in hospital and community healthcare settings. PLOS Pathog. 16, e1008817 (2020). doi:10.1371/journal.ppat.1008817 Medline

67. Y. J. Zhang, T. Hatziioannou, T. Zang, D. Braaten, J. Luban, S. P. Goff, P. D. Bieniasz, Envelope-dependent, cyclophilin-independent effects of glycosaminoglycans on human immunodeficiency virus type 1 attachment and infection. J. Virol. 76, 6332-6343 (2002). doi:10.1128/JVl.76.12.6332-6343.2002 Medline

68. F. Schmidt, Y. Weisblum, F. Muecksch, H. H. Hoffmann, E. Michailidis, J. C. C. Lorenzi, P. Mendoza, M. Rutkowska, E. Bednarski, C. Gaebler, M. Agudelo, A. Cho, Z. Wang, A. Gazumyan, M. Cipolla, M. Caskey, D. F. Robbiani, M. C. Nussenzweig, C. M. Rice, T. Hatziioannou, P. D. Bieniasz, Measuring SARS-CoV-2 neutralizing antibody activity using pseudotyped and chimeric viruses. J. Exp. Med. 217, e20201181 (2020). doi:10.1084/jem.20201181 Medline

69. M. Pizzato, O. Erlwein, D. Bonsall, S. Kaye, D. Muir, M. O. McClure, A one-step SYBR Green I-based product-enhanced reverse transcriptase assay for the quantitation of retroviruses in cell culture supernatants. J. Virol. Methods 156, 1-7 (2009). doi:10.1016/i.jviromet.2008.10.012 Medline

70. R. Zufferey, D. Nagy, R. J. Mandel, L. Naldini, D. Trono, Multiply attenuated lentiviral vector achieves efficient gene delivery in vivo. Nat. Biotechnol. 15, 871875 (1997). doi:10.1038/nbt0997-871 Medline

71. T. F. Rogers, F. Zhao, D. Huang, N. Beutler, A. Burns, W. T. He, O. Limbo, C. Smith, G. Song, J. Woehl, L. Yang, R. K. Abbott, S. Callaghan, E. Garcia, J. Hurtado, M. Parren, L. Peng, S. Ramirez, J. Ricketts, M. J. Ricciardi, S. A. Rawlings, N. C. Wu, M. Yuan, D. M. Smith, D. Nemazee, J. R. Teijaro, J. E. Voss, I. A. Wilson, R. Andrabi, B. Briney, E. Landais, D. Sok, J. G. Jardine, D. R. Burton, Isolation of potent SARSCoV-2 neutralizing antibodies and protection from disease in a small animal model. Science 369, 956-963 (2020). doi:10.1126/science.abc7520 Medline

72. H. Huerga Encabo, W. Grey, M. Garcia-Albornoz, H. Wood, R. Ulferts, I. V. Aramburu, A. G. Kulasekararaj, G. Mufti, V. Papayannopoulos, R. Beale, D. Bonnet, Human Erythroid Progenitors Are Directly Infected by SARS-CoV-2: Implications for Emerging Erythropoiesis in Severe COVID-19 Patients. Stem Cell Reports 16, 428-436 (2021). doi:10.1016/istemcr.2021.02.001 Medline

73. E. N. van den Brink, J. Ter Meulen, F. Cox, M. A. Jongeneelen, A. Thiijsse, M. Throsby, W. E. Marissen, P. M. Rood, A. B. Bakker, H. R. Gelderblom, B. E. Martina, A. D. Osterhaus, W. Preiser, H. W. Doerr, J. de Kruif, J. Goudsmit, Molecular and biological characterization of human monoclonal antibodies binding to the spike and nucleocapsid proteins of severe acute respiratory syndrome coronavirus. J. Virol. 79, 1635-1644 (2005). doi:10.1128/JVl.79.3.1635-1644.2005 Medline

\section{ACKNOWLEDGMENTS}

We are grateful to A.N. Engelman, A. Hayday, J.P. Stoye, J. Skehel, and A Karadimitris for comments on the manuscript, D. Benton, G.N. Maertens, and M. Vermeulen for helpful discussions, P. Walker and A. Purkiss for computer, software, and synchrotron access support, the staff of the Swiss Light Source PX1 beamline for assistance with data collection, Chris Wilson and Atul Goyale (UCLH Biochemistry) for their assistance with serum sample separation, and J. E. Voss for the kind gift of HeLa cells stably expressing ACE2. Funding: This research was supported by the Francis Crick Institute, which receives its core funding from Cancer Research UK, the UK Medical Research Council, and the Wellcome Trust. Work in P.C. laboratory was additionally supported by US National Institutes of Health grant P50 Al150481. The project was funded also by the King's Together Rapid COVID-19 Call award (KJD and MHM), the Huo Family Foundation (MHM and KJD) and by the UCL Coronavirus Response Fund made possible through generous donations from UCL's supporters, alumni and friends (LEM, LM). Flow cytometry was supported by a multi-user equipment grant from The Wellcome Trust to MHM and KJD (208354/Z/17/Z). LEM is supported by a Medical Research Council Career Development Award (MR/R008698/1). MJvG is a recipient of an AMC Fellowship, and RWS is a recipient of a Vici grant from the Netherlands Organization for Scientific Research (NWO). CG was supported by the MRC-KCL Doctoral Training Partnership in Biomedical Sciences (MR/N013700/1). MOM, EP and RST were supported in part by an UKRI/MRC Covid-19 grant (MC_PC_19078). EN, MJS, JH receive support from the UKRI COVID-19 research scheme. This study is part of the EDCTP2 program supported by the European Union (grant number RIA2020EF-3008 COVAB) (KJD and MHM). The views and opinions of authors expressed herein do not necessarily state or reflect those of EDCTP. This research was funded in whole, or in part, by the Wellcome Trust (FC001061). For the purpose of Open Access, the author has applied a CC BY public copyright license to any author accepted manuscript version arising from this submission. Author contributions: $A R, C R$, EC, AGW, and PC expressed and purified proteins; CR and SK established a stable cell line secreting trimeric SARS-CoV-2 spike; MSdS and JIMR conducted mass spectrometry; AR and VEP crystallised NTD-biliverdin complex; AN and PBR acquired and evaluated cryo-EM data; VEP collected and processed X-ray diffraction data, built and refined all atomistic models; AR and PC refined cryoEM structures; NC and LM conducted SPR measurements; AR performed thermostability assays; ELP, CRdO, MOM, and RST performed IgG capture ELISA; HR and AR did statistical modelling of IgG capture assay data; RU and RB evaluated SARS-CoV2 infectivity in the presence of biliverdin; AS and MP conducted pseudotype infectivity assays; C-ES, MF, JH, MS, GPT, and EN assembled the panels of human sera samples; MJvG, RWS, KJD, JS, and CG isolated or provided monoclonal antibodies; KWN and GK did flow cytometry assays with human sera; KJD, JS, CG, ELP, LEM, LMuir, MHM, and CR-S characterised monoclonal antibodies; PC, KJD, LEM, and GK wrote the paper with contributions from all authors. Competing interests: P. C., A. R. and. R. T. are inventors on a patent application related to the use of N121Q S1 for enhanced detection of SARS-CoV-2 antibodies in ELISA (indirectly related to data in Fig. S10.) UK Patent Application 2020199. Filed on 23, Dec. 2020. The authors declare no other competing interests. Data and materials availability: All manuscript data are available. The crystal structure of the NTD in complex with biliverdin and associated $X$-ray diffraction data are deposited with the Protein Data Bank under accession code 7B62. The cryo-EM maps and refined models of the trimeric SARS-CoV-2 spike are deposited with the EM Data Bank (EMD12585, EMD-12586, and EMD-12587) and Protein Data Bank (7NT9, 7NTA, and 7NTC), respectively. 


\section{SUPPLEMENTARY MATERIALS}

advances.sciencemag.org/cgi/content/full/sciadv.abg7607/DC1

Submitted 26 January 2021

Accepted 2 April 2021

Published First Release 22 April 2021

10.1126/sciadv.abg7607 

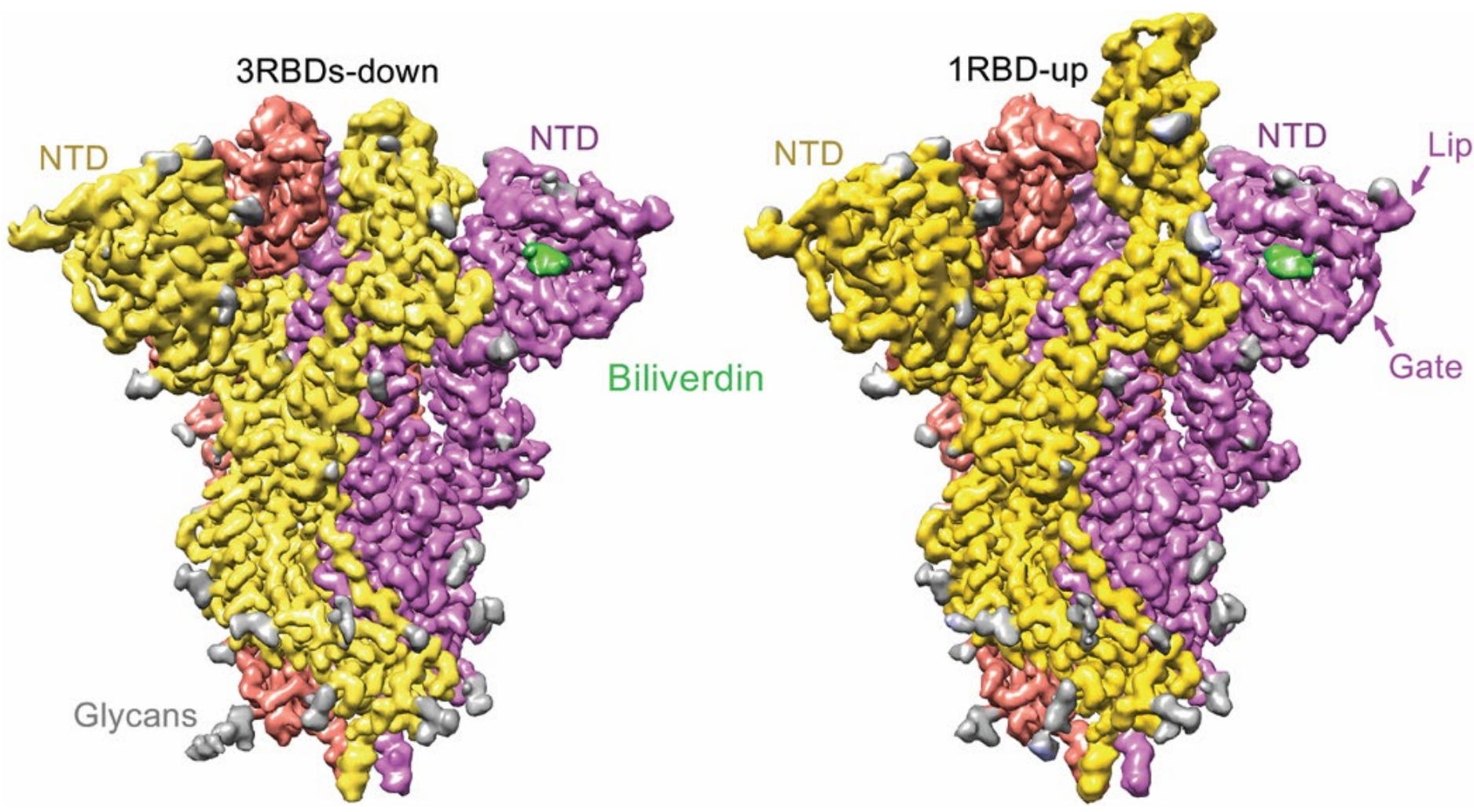

Fig. 1. Cryo-EM structures of the SARS-CoV-2 spike-biliverdin complex. 3D reconstructions of trimeric SARSCoV-2 spike ectodomain in 3RBD-down (left) and 1RBD-up (right) conformations determined under saturation with biliverdin. Spike protomers are color-coded. Biliverdin and glycans are shown in green and grey, respectively. 


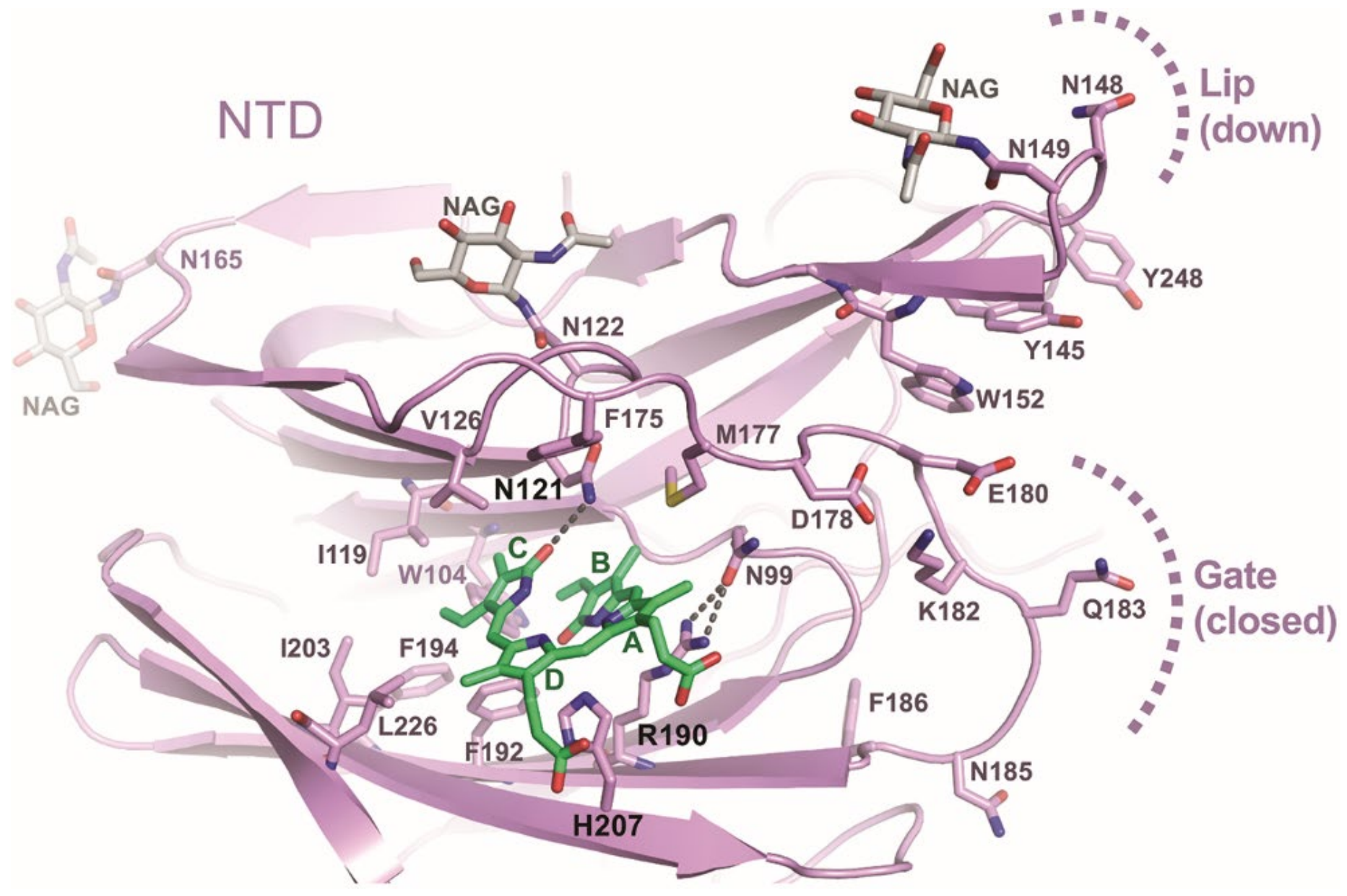

Fig. 2. Crystal structure of isolated SARS-CoV-2 spike NTD bound to biliverdin. Details of the biliverdin binding pocket in the crystal structure refined at $1.8 \AA$ resolution. SARS-CoV-2 NTD is shown as cartoons with selected amino acid residues and biliverdin in sticks. Carbon atoms of the protein chain, sugars (NAG), and biliverdin are in purple, grey and green, respectively; the remaining atoms are colored as follows: oxygen, red; nitrogen, blue; and sulfur, yellow. Dark grey dashes are hydrogen bonds. 

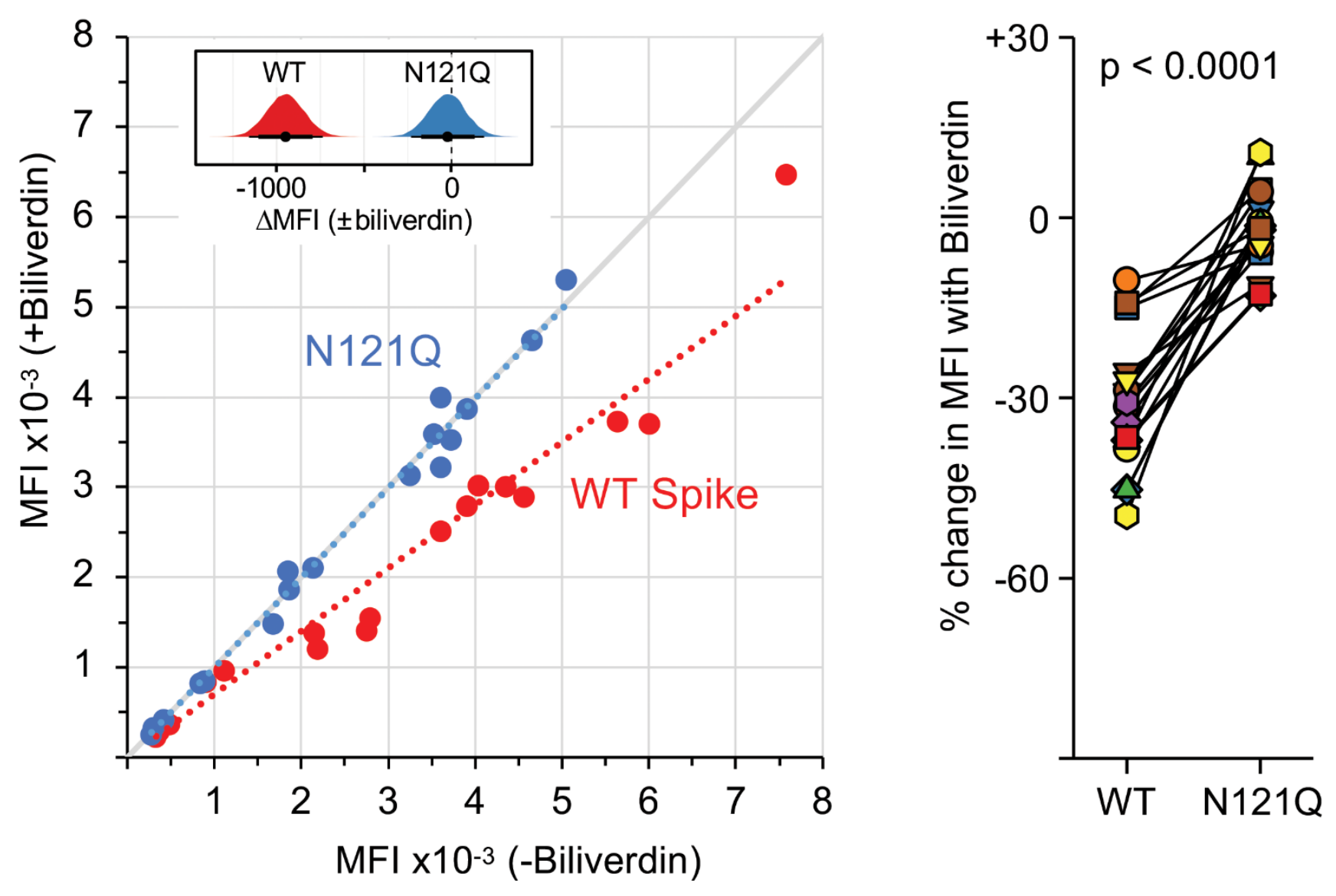

Fig. 3. Biliverdin strongly downmodulates the reactivity of SARS-CoV-2 spike with antibodies present in immune sera. Left: Mean fluorescence intensity (MFI) of IgG staining of HEK293T cells expressing full-length WT or N121Q SARS-CoV-2 spike by individual patient sera in the absence or the presence of $10 \mu \mathrm{M}$ biliverdin. Each symbol represents an individual patient $(n=17)$ and colored dotted lines represent the linear regression for each spike variant. The inset shows posterior probability density plots of values for pairwise contrasts ( \pm biliverdin) for the WT and N121Q spikes. Black dots indicate the median of the distribution, thick and thin line ranges correspond to the $85 \%$ and $95 \%$ highest density interval, respectively; the dotted vertical line indicates a zero difference. Right: Changes in MFI caused by the addition of $10 \mu \mathrm{M}$ biliverdin, as percent of staining without biliverdin, for serum for IgG antibodies. Each pair of connected symbols represents an individual patient. The $p$ value reported above the plot was calculated using a two-tailed paired Student's t test comparing the effect of biliverdin (\% change in binding) on the WT spike versus the effect of biliverdin on the N121Q spike for each serum sample. 

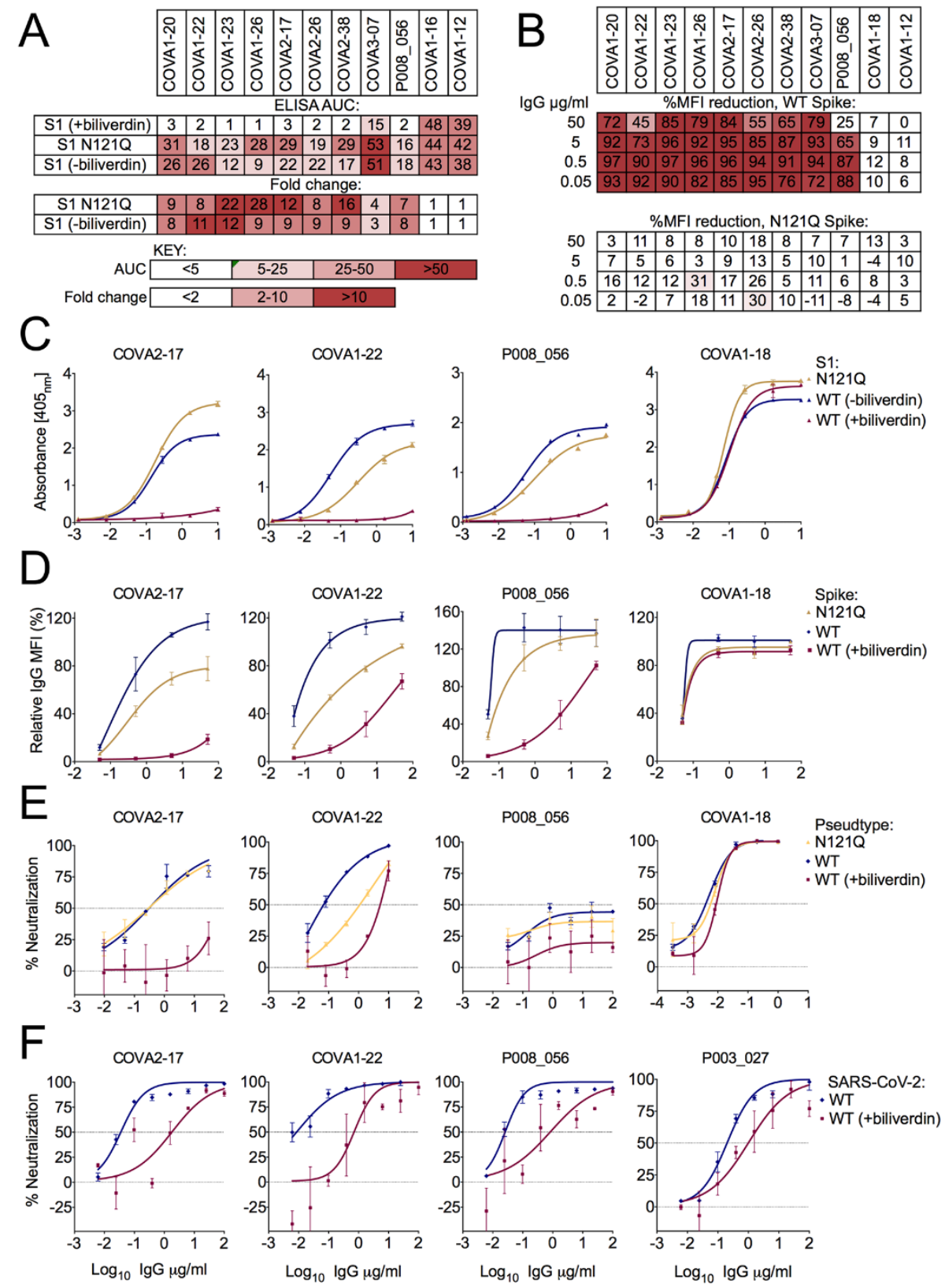

Fig. 4. Biliverdin decreases binding to SARS-CoV-2 spike by a group of human monoclonal IgGs. (A) Antibodies were titrated 6-fold and assayed by direct ELISA for binding to recombinant S1 biliverdin-depleted by purification under acidic conditions (-biliverdin), same protein but supplemented with biliverdin (+biliverdin) or N121Q S1. Area under the curve (AUC) is shown for IgG that were sensitive to biliverdin and two unaffected control lgGs. AUC values are color-coded as per the key; fold change compared to WT protein are reported. (B) Biliverdin-sensitive IgGs were titrated 10-fold and incubated with 293T cells expressing full-length WT or N121Q SARS-CoV-2 spike with or without $10 \mu \mathrm{M}$ biliverdin. Binding was detected using an anti-lgG antibody and reduction in binding in the presence of biliverdin is shown as \% MFI reduction and color-coded as a heatmap of the quartile values. (C) ELISA titration curves for four neutralizing IgG including the biliverdin-insensitive control COVA1-18. (D) Relative MFI dose-dependent curves for four neutralizing IgG including the biliverdin insensitive control COVA1-18. Relative MFI calculated by normalising to the MFI of the biliverdin-insensitive COVA1-18 at the highest concentration against spike. (E) IgG indicated above each graph were titrated 5-fold against SARS-CoV-2 spike pseudotype, in the presence and absence of $10 \mu \mathrm{M}$ biliverdin, and a version of spike encoding the mutation N121Q. COVA1-18 was used as a biliverdin-insensitive control lgG. (F) Neutralization of SARS-CoV-2 (England 02/2020/407073) by lgGs was measured in the absence and presence of 10 $\mu \mathrm{M}$ biliverdin in Vero-E6 cells. P003_027 was used as a biliverdin-insensitive control lgG. 


\section{A}
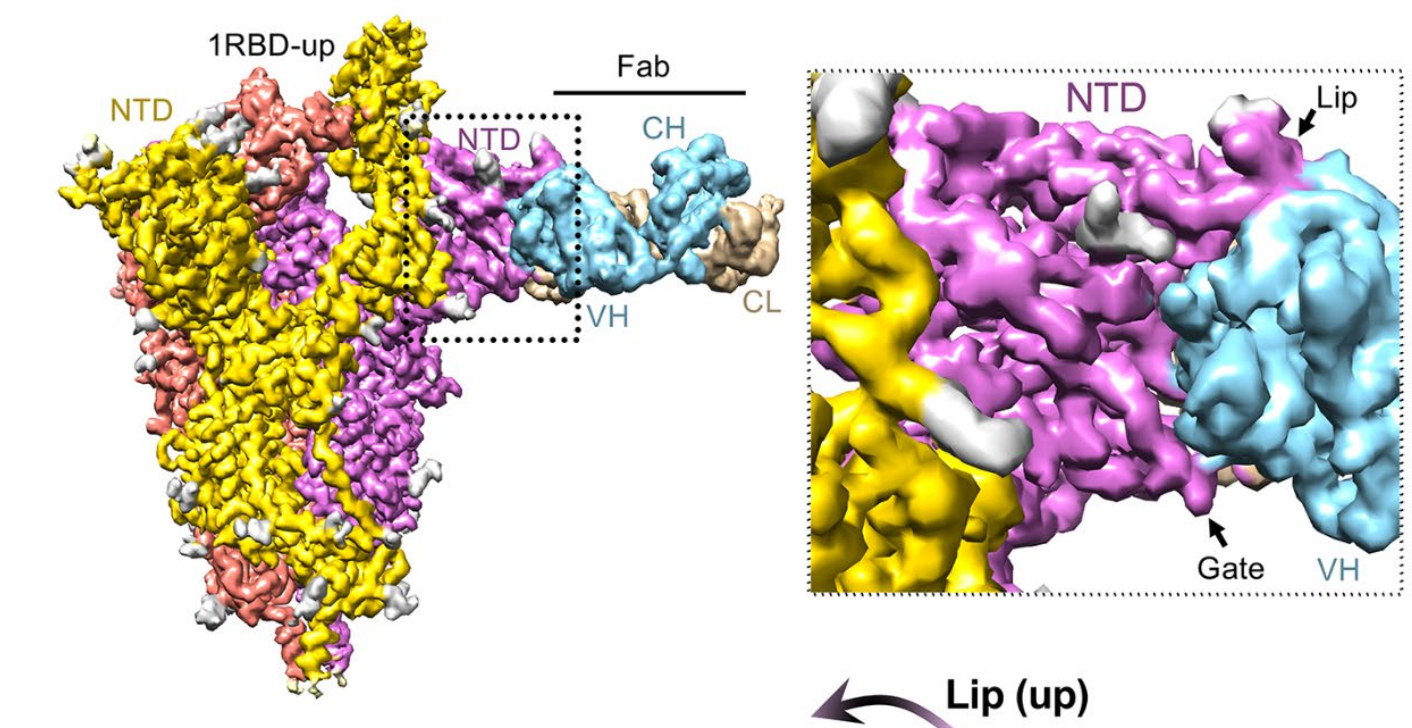

B

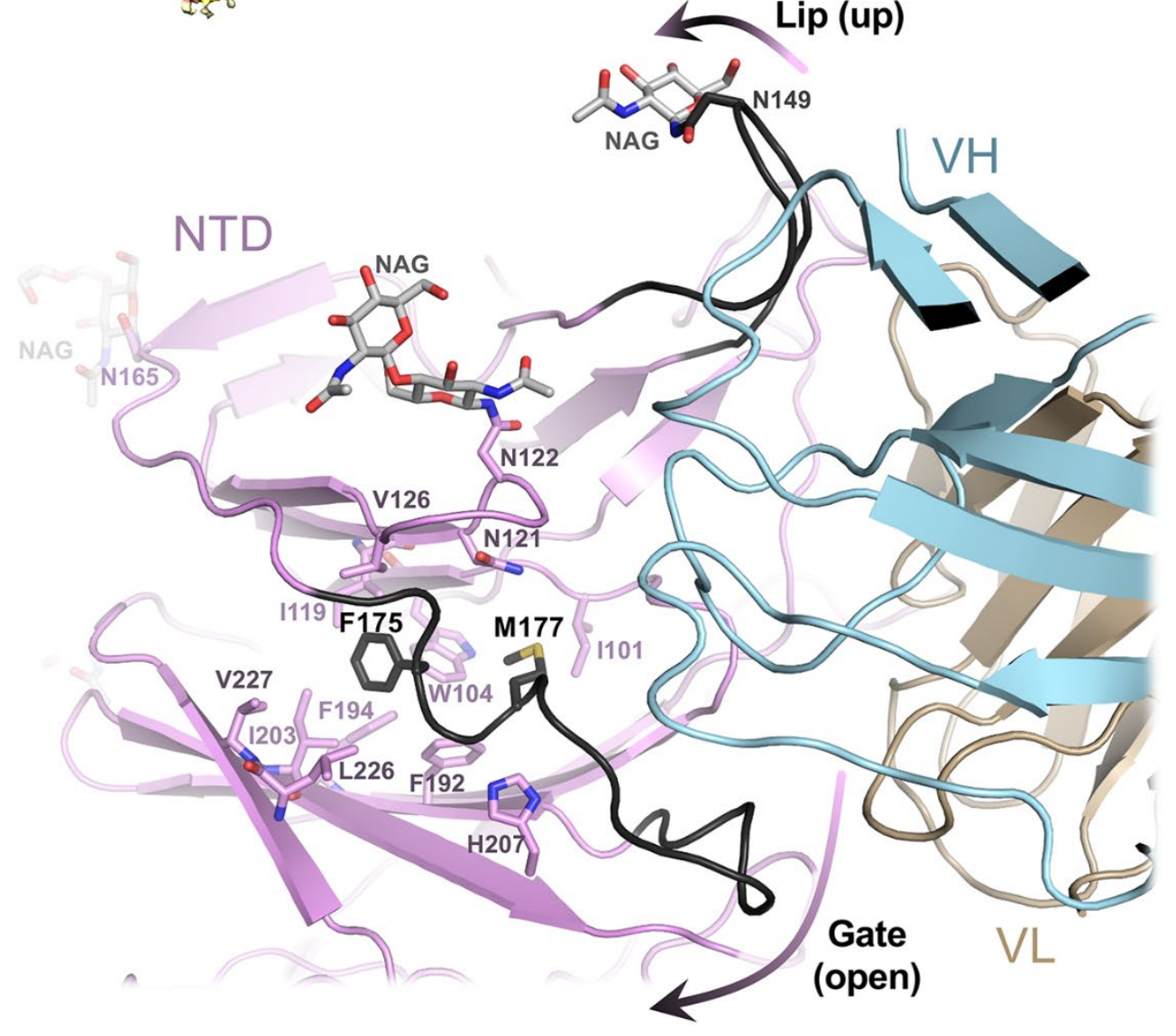

Fig. 5. Cryo-EM structure of the spike-Fab complex. (A) Reconstruction obtained with multibody refinement in Relion (left) and a zoom on the spike-Fab interface in the structure obtained by consensus refinement (fig. S12d). (B) Refined model of the spikeFab complex shown as cartoon, with selected amino acid side chains in sticks and indicated. Carbon atoms of the gate and lip NTD elements that relocate to allow Fab binding (arrows), are shown in black. Fab heavy (HV) and light (LV) chains are shown in blue and beige, respectively. 